\title{
Las organizaciones comunitarias del agua en el estado de Veracruz. Análisis a la luz de la experiencia latinoamericana
}

\section{Community water organizations in the state of Veracruz. Analysis in light of the Latin American experience}

\author{
Judith Domínguez Serrano* \\ Erandi Castillo Pérez**
}

\section{Resumen}

México comparte con la región latinoamericana la experiencia de más de cincuenta años de gestión comunitaria del agua; sin embargo, si bien existen organizaciones constituidas para el autoabastecimiento del líquido en zonas rurales y periurbanas, éstas no han experimentado el fortalecimiento que se observa en otros paises. En este artículo se presenta un análisis realizado en Veracruz, la entidad con mayor número de localidades rurales en el país, y una de las que mayor rezago tiene en la cobertura de agua potable, drenaje y alcantarillado.

En el ámbito latinoamericano, las organizaciones comunitarias de servicios de agua y saneamiento (OCSAS) han desplegado diversas estrategias para su fortalecimiento; entre ellas figura la asociatividad como punto clave para la sostenibilidad de los sistemas hídricos en el área rural, que no se observa en México pues no existen ahi las condiciones institucionales para fortalecer este tipo de organización social, que permitiría dar cumplimiento al derecho humano al agua en las zonas rurales donde el Estado no llega.

Palabras clave: organizaciones comunitarias de servicios de agua y saneamiento; asociatividad; acceso al agua; zonas rurales; zonas periurbanas.

* El Colegio de México, A.C., coordinadora académica del doctorado de Estudios Urbanos y Ambientales. Dirección postal: Carretera Picacho Ajusco 20, Ampliación Fuentes del Pedregal, 14410, Tlalpan, Ciudad de México. Correo electrónico: judithdominguez@colmex.mx

** El Colegio de México, A.C., Centro de Estudios Urbanos y Ambientales, asistente de investigación. Dirección postal: Carretera Picacho Ajusco 20, Ampliación Fuentes del Pedregal, 14410, Tlalpan, Ciudad de México. Correo electrónico: eacastillo@colmex.mx 


\begin{abstract}
Mexico shares with the Latin American region the experience of more than fifty years of community water management; in other words, there are organizations that have been created for the self-supply of water in rural and peri-urban areas, although they have not been strengthened as they have in other countries. This article presents an analysis conducted in Veracruz, the state with the highest number of rural localities in the country and one of those that lag furthest behind in drinking water, drainage and sewage coverage.

In Latin America, community organizations for water and sanitation services (OCSAS) have employed various strategies to improve their functioning. Associativity is a key point for the sustainability of water systems in rural areas, which is not observed in Mexico due to the lack of institutional conditions to strengthen this type of social organization, which would make it possible to enforce the human right to water in rural areas where the State is not present.
\end{abstract}

Keywords: community organizations for water and sanitation services; associativity; access to water; rural zones; peri-urban areas.

\title{
Planteamiento
}

Las organizaciones comunitarias de servicios de agua y saneamiento (OCSAS) "son estructuras sociales creadas por grupos de vecinos, en zonas periurbanas o rurales, donde generalmente los servicios públicos o privados no se brindan" (CLOCSAS, 2012); incluso se puede añadir a los fraccionamientos urbanos que, contando con una concesión por el líquido, autoadministran el sistema de agua de una urbanización dentro del ámbito municipal. Se estima que tan sólo en Latinoamérica y el Caribe, un rango de $20 \%$ a $40 \%$ de la población por país es atendida por las OCSAS, y que alrededor de ochenta mil de éstas abastecen aproximadamente a más de setenta millones de personas en la región (Marín, 2016). En varias naciones de América Latina las OCSAS han permitido enfrentar problemas de abasto de agua en zonas de difícil acceso (y en las que no lo son) en ámbitos rurales o periurbanos. En algunos países tal modalidad ha sido fomentada y apoyada por el Estado nacional y ha resultado una vía exitosa para atender estas zonas con sostenibilidad, mediante servicios que van más allá de la dotación del líquido, y se extienden, en algunos casos, al alcantarillado y al tratamiento de aguas.

Aun contando con las experiencias de asociatividad de las OCSAS en América Latina, en México no existe una experiencia similar. En distintas entidades federativas del país hay algún tipo de organización comunitaria que gestiona el recurso hídrico u otros recursos naturales, como los bosques, pero la mayoría carece de una estructura sólida que les permita dotarse de 
agua con sostenibilidad económica. Se han documentado casos excepcionales en los que se muestra una fortaleza organizacional (como en el agua para riego, que Palerm ha estudiado), y se referirán en este trabajo como contexto del estudio de caso.

En este artículo se explica la organización social documentada por la Comisión Estatal de Aguas del Estado de Veracruz (CAEV), y se exponen los resultados del análisis de varios comités de agua en el ámbito rural y periurbano, con trabajo de campo y formación de grupos focales con miembros de los comités de agua. Se identifican los aspectos que deben atenderse para transitar a la gestión comunitaria del líquido en forma fuerte, sostenible y empoderada; con capacidad de diálogo con los gobiernos para solicitar apoyos, colaborar en el abastecimiento de agua a las poblaciones, y con habilidades para atender los sistemas hídricos cuando requieran reparación.

Veracruz es la entidad con mayores localidades rurales; cuenta con 20828 localidades (INEGI, 2010), de las cuales 20513 son rurales, es decir, tienen menos de 2500 habitantes. Datos oficiales de la Comisión Estatal de Agua (CAEV) estiman que existen alrededor de 2000 OCSAS, y de éstas, 1425 tienen prácticas autogestivas y 646 son administradas por la CAEV. Veracruz es rico en agua; es el segundo estado en el país con mayor abundancia hídrica, pero tal virtud es relativa porque tratándose del acceso al líquido, se observan deficiencias e incluso su falta en los hogares, lo que evidencia las limitaciones del servicio público, particularmente en los ámbitos rurales y periurbanos, que aquí nos interesan. La incapacidad institucional municipal para gestionar los servicios públicos ha derivado en que varios de sus ríos se encuentren muy contaminados, en el déficit en la prestación de tales servicios y en el escaso tratamiento de las aguas residuales. En el medio rural la falta de atención municipal ha llevado a que sea la CAEV quien gestione directamente el abastecimiento en varios municipios, o que sea la propia comunidad quien autoadministre los rudimentarios sistemas rurales hídricos. Aunque en algunas etapas hubo mayor apoyo, control y registro sobre el funcionamiento de los mismos, esta práctica se abandonó cuando los factores políticos tuvieron mayor peso sobre los de la racionalidad técnica en la administración del agua en el estado.

\section{Marco teórico y metodológico}

La gestión comunitaria del agua es un tema que se analiza desde distintas perspectivas epistémicas, principalmente desde la antropología social y la sociología rural con los trabajos de Castro (2006), Torregrosa y Kloster (2006) 
y Castro y Lacabana (2005), en los que se describen las interrelaciones entre la gestión del líquido, la conflictividad social y las formas de participación y el ejercicio de los derechos de la ciudadanía; autores como Barlow (2007) documentan casos internacionales donde la participación social ha permitido una mejora en el autoabastecimiento del agua o el cuidado de sus recursos naturales. Desde el punto de vista de la gobernanza, se encuentran los trabajos que analizan la administración colectiva de los recursos de uso común (Ostrom, 2000); la gestión de los recursos naturales comunes (Merino, 2004); la gestión social del agua de riego de manera sostenible y participativa (Palerm, 2002; Jiménez, 2011); la creación de capital social para aumentar la acción colectiva y mejorar la gestión hídrica (Paré, 2005); y las metodologías participativas para resolver problemas en torno al uso de los recursos comunes en un mismo espacio o territorio (Cárdenas, 2009).

La experiencia latinoamericana muestra un aumento en el acceso al agua mediante el fortalecimiento de la comunidad, la asociatividad y la creación de capital social. La pregunta que guía este trabajo es, ¿por qué no existe asociatividad en Veracruz si hay una organización social de base que se autoabastece del fluido en lugares donde el Estado en su conjunto no ha llegado? Y en segundo lugar, ¿cuáles son los aspectos que deben atenderse o priorizarse en la política del subsector agua potable y saneamiento para fortalecer esta organización social y dar sostenibilidad a los sistemas hídricos en las zonas rurales? A pesar de que en México existe un programa de subsidios para atender dichas zonas, los efectos positivos en la organización social son modestos, pues la dispersión territorial ha sido una excusa para la atención oportuna de tales zonas, y poco se ha invertido en el fortalecimiento o creación de capital social. No se cree en este tipo de organización y se esgrimen argumentos legales para no reconocerla, tales como la exclusividad municipal para la prestación del servicio público, la anualidad de los programas presupuestarios o la ineficiencia de los comités de agua rurales.

La metodología que se siguió para realizar esta investigación fue cualitativa. Para Latinoamérica se revisaron artículos, libros y tesis al respecto, y particularmente se analizó la experiencia de la Confederación Latinoamericana de Organizaciones Comunitarias de Servicios de Agua y Saneamiento (CLOCSAS). Para el caso de Veracruz, además de la revisión mencionada, se realizaron entrevistas semiestructuradas a personas clave y grupos focales, y se revisó la base de datos de Conagua sobre comités rurales en la entidad a nivel localidad y municipio, de 2009 a 2013. También se estudió el marco normativo estatal de agua. Para presentar los datos sobre la creación y el funcionamiento de los comités rurales apoyados por el Programa para la Construcción y Rehabilitación de Sistemas de Agua Potable y Saneamiento 
en Zonas Rurales (Prossapys) en Veracruz, se consultaron los anexos técnicos correspondientes al periodo 2009 a 2013. La unidad de análisis fueron los patronatos de agua, y se realizaron entrevistas y grupos focales en 2012 en la Zona Metropolitana de Xalapa (Castillo, 2012). En este artículo se considerarán las OCSAS, denominación que se acuñó para agrupar a las diversas organizaciones comunitarias que se autoabastecen de agua.

Una parte de los grupos focales y de las entrevistas semiestructuradas se centraron en los tipos de vinculación de estos patronatos con sus pares, los actores gubernamentales y los actores privados. En el municipio Emiliano Zapata se realizaron entrevistas en las localidades de a) La Estanzuela, b) El Chico, c) Dos Ríos, d) El Lencero, y en la e) Comisión Municipal del Agua y Saneamiento de Emiliano Zapata. En esta zona se contactaron a $f$ ) otros informantes, y finalmente se realizó un grupo focal en g) El Castillo, municipio de Xalapa (véase el Mapa 1).

Se entrevistó a dos participantes de la asociación civil j) Consejo de Cuenca del Río Pixquiac (Cocupix), quienes trabajan de cerca con las organizaciones comunitarias de los municipios de Tlalnehuayocan, Perote, Xalapa y Coatepec. Asimismo, en el municipio de $k$ ) Tlalnehuayocan se realizaron dos entrevistas, una al director de Recursos Humanos del municipio y otra al presidente de una organización en la colonia El Arenal. Se aplicó una entrevista a la l) Comisión Municipal del Agua de Coatepec en el Departamento de Cultura del Agua. La información obtenida en campo durante 2012 fue complementada con entrevistas realizadas al área de planeación de la CAEV y con datos estadísticos de las organizaciones sociales del estado de Veracruz.

\section{La asociatividad en las OCSAS}

El término asociatividad en la gestión comunitaria del agua surgió como una de las estrategias impulsadas desde los actores encargados de la gestión para favorecer los vínculos con los sectores públicos e ir más allá de la autogestión de escala local. Según la CLOCSAS es un

proceso institucional de articulación, intercambio, comunicación y coordinación entre organizaciones comunitarias de agua y saneamiento de una localidad, región, país o continente, con el fin de aprender y fortalecer sus capacidades (de gestión, de incidencia en políticas públicas, de innovación) de manera sostenible, orientadas en el propósito común del acceso al agua y al saneamiento para más latinoamericanos [CLOCSAS, 2012, p. 5]. 


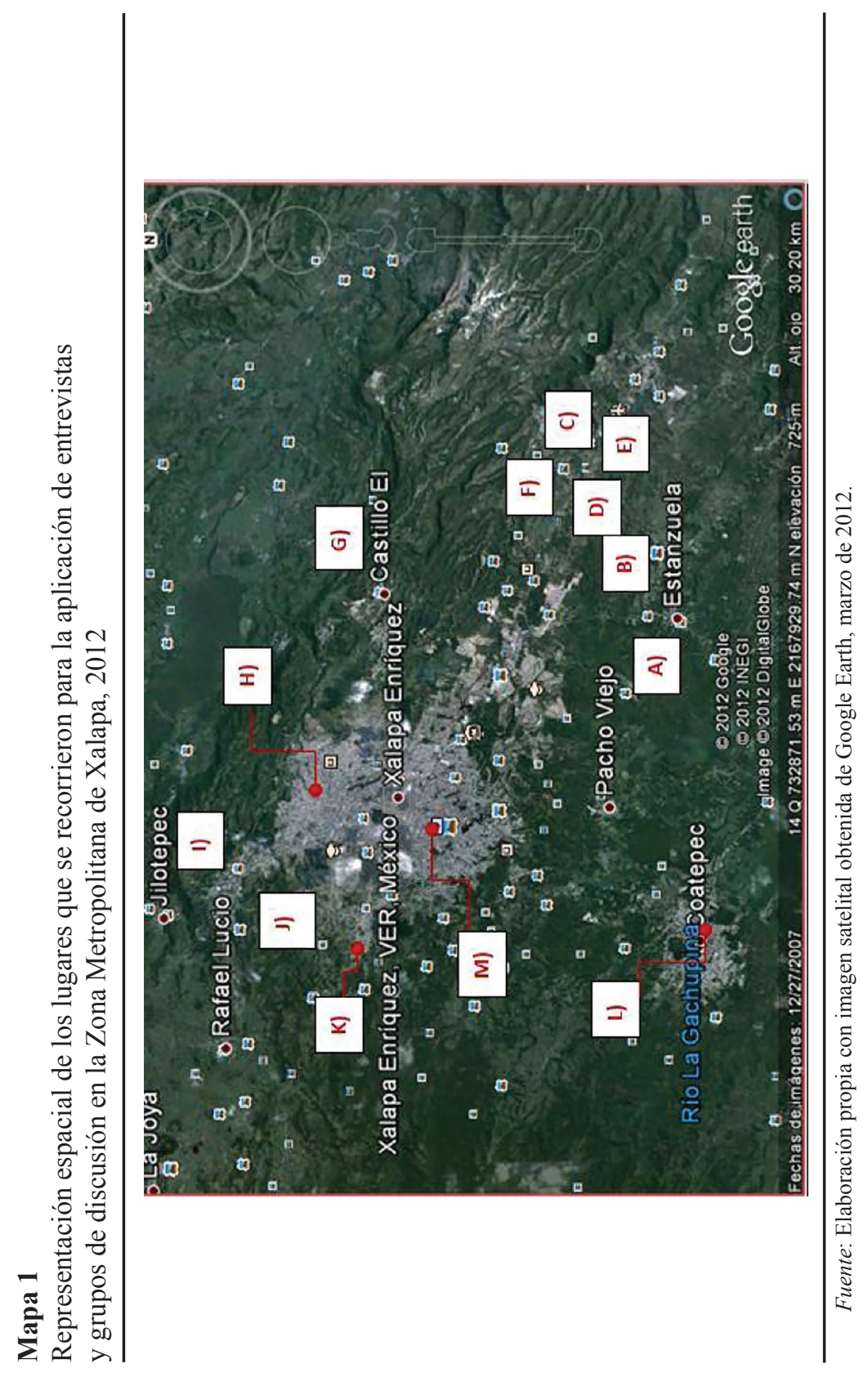


La autogestión - que es la autonomía de cada comunidad en relación con alguna instancia gubernamental o no gubernamental- y la asociatividad pudieran entenderse como prácticas contradictorias, dado que la asociatividad implica la articulación entre OCSAS, quizá con las instancias mencionadas y más allá de las acciones realizadas en los límites de su territorio. No obstante, las experiencias latinoamericanas no muestran tal contradicción, sino, por el contrario, son independientes y/o colaboran con los gobiernos locales.

Con el fin de evitar esta contradicción, se proponen conceptos como cogestión o corresponsabilidad (Dupuits, 2014, p. 3) para resignificar el proceso de colaboración. Dupuits $(2014$, p. 2) observa que se justifica esta redefinición por el objetivo de fortalecer las capacidades técnicas y financieras de las OCSAS mediante la construcción de alianzas con los actores públicos. Así, la asociatividad se vislumbra como la estrategia a seguir "como una garantía de sobrevivencia del modelo comunitario mismo" (Dupuits, 2014, p. 3; Zambrana, 2017, p. 16).

Incluso se hace hincapié en que, por un lado, la gestión comunitaria es "el modelo de gestión autónomo bajo el cual una comunidad se organiza y establece sus propias reglas para el aprovechamiento del recurso" (Lockwood, 2002; Bernal, Rivas y Peña, 2014, pp. 161-162), y por otro, la gestión colaborativa y/o cogestión es "un modelo de gestión heterónomo en el que interviene el Estado desde el gobierno central y local, el sector privado, las comunidades y la sociedad civil" (Bernal, Rivas y Peña, 2014, p. 162); en este último caso interesa el fortalecimiento de la gestión comunitaria y el desarrollo de la localidad. Ahora bien, la asociatividad puede darse a distintas escalas: local, regional, continental y transcontinental.

\section{La asociatividad en la regional latinoamericana}

En Chile las asociaciones de agua potable rural (APR) están constituidas principalmente como comités y cooperativas; existen aproximadamente 1500 y son gestionadas por más de 1700 dirigentes que trabajan de forma honoraria, es decir, sin pago alguno. Su actuación se ha considerado exitosa dado el modelo público comunitario de abastecimiento del líquido (Villarroel, 2012, p. 3). Dichas organizaciones se han agrupado desde el año 2005 en la Federación Nacional de Agua Potable Rural (Fenapru), una plataforma desde la cual se plantean los temas prioritarios de los comités y cooperativas de agua en el medio rural. Un ejemplo de lo descrito es la aprobación del proyecto de Ley de Servicio Sanitario Rural, que se elaboró 
con la participación ciudadana y fue aprobada por unanimidad en enero de 2017 por ambas cámaras. Este es un hecho importante en Chile, puesto que establece un marco regulatorio para los servicios de agua potable rural que protege y regula la administración comunitaria, limita la privatización, incluye el saneamiento, y define los derechos y deberes de las cooperativas y los comités, así como las funciones del Estado para los servicios de agua potable rural (Fenapru, 2017).

En el caso de Ecuador, la asociatividad entre las OCSAS (en ese país se llaman Juntas Administradoras de Agua Potable y Alcantarillado) tienen reconocimiento legal; en la Ley Constitutiva de Juntas Administradoras de Agua Potable y Alcantarillado se les faculta para la celebración de convenios; y el artículo 318 de la Constitución establece que el Estado debe fortalecer dichas iniciativas comunitarias (Fondo para el Logro de los ODM, 2013, p. 37). La asociatividad entre las OCSAS de Ecuador se considera como una necesidad para garantizar la conservación, la recuperación y el manejo integral de los recursos hídricos, dado que se busca ir más allá de los objetivos de los respectivos sistemas de agua potable y saneamiento de las Juntas Administradoras de Agua Potable y Alcantarillado; podría decirse que buscan presentar un sistema hídrico de interés público, colectivo y desde una gobernabilidad local (Guerrero-de León et al., 2010, p. 355). La asociatividad de las OCSAS en el ámbito local ocurre cuando comparten un territorio, pero sobre todo cuando estas estructuras comunitarias comparten una cuenca, microcuenca o una misma fuente del fluido (Fondo para el Logro de los ODM, 2013, p. 35). Para dar respuesta a este enfoque de gestión integral del recurso se constituyó el Centro de Apoyo a la Gestión Rural del Agua Potable, como una alianza público comunitaria del cantón Cañar con 95 OCSAS (Juntas Administradoras de Agua Potable Rurales) (Guaillas, 2013).

En Argentina se han constituido cooperativas de agua, apoyadas por el ente rector del subsector (AYSA, Asociación de Agua y Saneamiento), que funcionan no sólo en los ámbitos rurales.

En Centroamérica se pueden documentar varios casos donde se encuentran buenas prácticas para aumentar la cobertura en zonas rurales críticas por la falta de agua, para su saneamiento y para promover el reconocimiento legal de la gestión comunitaria, principalmente en las zonas rurales, pero no exclusivamente (Guatemala, Nicaragua, El Salvador, Costa Rica y Panamá).

No obstante, también se ha documentado que las relaciones bilaterales OCSAS-municipio pueden favorecer relaciones paternalistas, clientelistas y de aprovechamiento político. Es por ello que se subraya el necesario cuidado de la autonomía relativa de las OCSAS mediante una alianza multiactor, para no reemplazar a los actores en su quehacer específico (Cenagrap, 2011, p. 84). 


\section{La asociatividad y el papel de las organizaciones comunitarias para el abastecimiento de agua en México}

La asociatividad, entendida en los términos expuestos, no ha logrado consolidarse en México; si bien existen experiencias documentadas ${ }^{1}$ (Palerm y García Blanco, 2003), no existe una política de Estado que la propicie. La organización social se encuentra en menor escala en un conjunto de localidades rurales, por ejemplo, en comunidades del estado de Hidalgo; Galindo y Palerm (2009) han documentado el caso de San Miguel Tazintla, donde se encuentra una organización que abarca varios municipios y localidades; otros investigadores han estudiado organizaciones para la protección de la cuenca a partir de la inversión social para la sustentabilidad (Paré, 2005); y algunos más, otras abocadas al uso del agua de riego (Jiménez, 2011, p. 337).

La organización comunitaria para el abastecimiento de agua en México ha surgido para la realización de las faenas de las obras que la propia comunidad construye, teniendo además un sistema de castigos o penalidades reconocidos socialmente. Esta organización se da para abastecerse de agua de fuentes cercanas, canalizándola hacia los hogares (como en Hidalgo), pero también hay casos documentados en que se realiza un manejo más integrado, que abarca agua, bosques y suelo (Programa Agua para Siempre, Alternativas y Procesos de Participación Social A.C., 2017).

Ahora bien, a la luz de la experiencia latinoamericana, donde en la mayoría de los países existe apoyo del gobierno y reconocimiento legal, surge el cuestionamiento, ¿qué ha faltado en México para dar este paso?

En el país existen programas federalizados de subsidios dirigidos a entidades y municipios, específicamente el Proagua, con sus componentes para zonas urbanas y rurales, y concretamente el programa Prossapys, donde hay un componente de fortalecimiento social, que en 2016 constituyó $2.5 \%$ del total del presupuesto (Hernández, 2016); entre sus reglas de operación considera la conformación de comités de agua y comités de contraloría social que, sin embargo, no han tenido continuidad. Esa es la principal carencia de los programas federalizados, que no logran trascender las reglas administrativas, lo cual repercute en un menor efecto en la atención de la falta de agua, pues se construyen sistemas, pero no se orientan hacia la sostenibilidad de los mismos.

1 Se han realizado hasta ahora tres foros de Manejo Comunitario del Agua: en el año 2007; en 2009, en Guerrero y con representantes de Veracruz y Chiapas; y en 2011, también en Guerrero, pero prácticamente sólo con representantes de dicha entidad (González, Chávez y Silva, 2011). 
Si bien el auge del concepto de la descentralización del agua tomó mayor fuerza en la década de los ochenta, la responsabilidad de la operación, administración, mantenimiento y supervisión de los sistemas rurales del agua para el consumo humano ha sido ambigua desde la década de los cincuenta. En la práctica, los sistemas hídricos rurales construidos presentaban diversas necesidades imposibles de ser atendidas en su totalidad desde la federación; es por ello que el capital social, entendido como "el conjunto de condiciones que permiten resolver los problemas que surgen en torno a la acción colectiva" (Jackman y Miller, 1998; Ostrom y Ahn, 2003; Merino, 2008), construido mediante la formación de comités y subcomités, subsistió en algunas zonas, se difuminó en otras, y en algunos casos volvió a surgir con el objetivo de gestionar sus demandas con las autoridades, o para tratar de solucionar la falta de agua con sus propios medios y recursos.

En la década de los cincuenta, para la construcción de los sistemas rurales hídricos, desde el gobierno federal se organizaban comités de obra para que coordinaran los trabajos de introducción de la infraestructura; por su parte, la población designaba a un representante, el cual sería el portavoz entre los ciudadanos y el gobierno (López, Martínez y Palerm, 2013, p. 40). En este sentido, se les delegaban funciones de coordinación, supervisión y cobro a representantes locales de las poblaciones rurales por un tiempo determinado, hasta que la obra fuese concluida. Sin embargo, la organización comunitaria siempre ha estado presente en múltiples formas para subsanar, en la medida de sus posibilidades, aquellos huecos donde la acción pública estatal no llega. Se han documentado prácticas de autoadministración de los sistemas hídricos y protección de la cuenca (Paré, 2005) que confirman que existen experiencias descentralizadas del agua, aunque, desde un enfoque formal de la administración pública, no lo sean en estricto sentido.

Uno de los principales problemas de la política pública para proveer del servicio a las localidades rurales ha sido precisamente el no considerar mecanismos de seguimiento a mediano y largo plazos a posteriori de la construcción de la infraestructura, que consideren la capacidad real en términos de costos para el mantenimiento de los sistemas. La sostenibilidad de los sistemas rurales hídricos no ha sido posible por parte de la federación porque sus recursos humanos y económicos se ven rebasados, de igual forma sucede con los gobiernos estatales y municipales. La modificación al artículo 115 constitucional, al dar mayor autonomía financiera, económica y política a los municipios, los puso a prueba en el cumplimiento de la provisión de agua potable y saneamiento, y hoy en día, si evaluamos los resultados, la mayoría de ellos no logró construir una capacidad institucional para gestionar de forma eficiente los servicios públicos (Domínguez, 2010), mucho menos en el ámbito rural. 
Las transferencias federales a los estados para la construcción de sistemas de agua en los noventa mejoraron la cobertura del líquido y su saneamiento en el medio rural; sin embargo, los estados y municipios se han vuelto dependientes de este financiamiento, que es preocupante, ya que no se han fortalecido esquemas locales para sostener los sistemas construidos. A pesar de que el objetivo esencial de la descentralización era que la sociedad encontrara una solución más rápida a sus problemáticas y que se instrumentaran respuestas diferenciadas a sus demandas, lo cierto es que ante las omisiones y ambigüedades en los marcos jurídicos estatales y municipales, aunadas a la deficiente capacidad de los gobiernos locales para atender a una población diseminada en el territorio -en condiciones topográficamente complejas-, una buena parte de la población rural ha optado por la autogestión y autoadministración de los sistemas rurales de agua. Esta modalidad está considerada en algunos estados o municipios, que con previa autorización pueden conformar asociaciones civiles para autoabastecerse del líquido, aunque la realidad es que muchos sistemas rurales operan en la informalidad, pues no se conocen los términos, condiciones y limitantes en los que operan.

\section{Descripción de la zona de estudio: Veracruz, el estado con mayor número de localidades rurales}

De acuerdo con Palma, Quesnel y Delaunay (2000, p. 83) en las décadas de los ochenta y noventa se continuaron a lo largo del territorio mexicano dos procesos: por un lado, la concentración urbana, y por el otro, la dispersión rural. Adicionalmente, también se presentó un proceso de extensión del espacio urbano al rural, generando la conurbación de las localidades rurales localizadas en las proximidades de los polos urbanos.

En cuanto al estado de Veracruz, de 1970 a 1990 se duplicó su población, concentrándose cerca de la mitad en localidades de más de 15000 habitantes, con altas tasas de crecimiento de población rural en los municipios costeros del golfo de México y en la región sur de la entidad. En la zona central se dio también una dinámica de poblamiento a consecuencia de la reforma agraria, la cual implicó la instalación de pequeñas poblaciones en el ejido y su diseminación, creando nuevos asentamientos a partir de las ampliaciones del ejido (Palma, Quesnel y Delaunay, 2000). En las zonas rurales de la entidad habitan 2.8 millones de personas, el resto de la población se ubica en zonas urbanas.

El reordenamiento de las poblaciones rurales en el estado de Veracruz ha presentado diversos comportamientos. En el municipio de Tuxpan la 
población se aglomeró en la cabecera municipal, a la par que se presentó un proceso de acentuada dispersión demográfica en un gran número de localidades de menos de 100 habitantes. En el municipio de Álamo, conocido por su auge de producción citrícola, la concentración poblacional se localizó en las localidades rurales más acomodadas (Palma, Quesnel y Delaunay, 2000, p. 93). En los municipios de las Altas Montañas la población se conservó prácticamente igual, e incluso a partir del nuevo milenio experimentó una fuerte migración, dejando despoblado el campo. Otro fenómeno en el territorio rural fue la "indigenización" del campo, como sucedió en la Huasteca y en el Sotavento, dado que la población rural, principalmente mestiza, se movió hacia las periferias de los polos regionales (Palma, Quesnel y Delaunay, 2000, p. 93).

El estado de Veracruz ocupa el cuarto lugar de marginación en el país, después de Guerrero, Chiapas y Oaxaca. En 2010, $2.6 \%$ de los ocupantes de viviendas de la entidad se encontraban sin drenaje ni excusado, y $19.5 \%$ sin agua entubada; $39.9 \%$ de las viviendas presentaban hacinamiento, y $46.2 \%$ de la población estaba asentada en localidades menores de 5000 habitantes. Del total de localidades, 40.9 \% tenía un grado de marginación muy alto o alto, y en su mayoría correspondían a localidades rurales (Conapo, 2010) (véase el Mapa 2).

\section{Organización comunitaria y evolución de la cobertura de agua potable, drenaje y alcantarillado en las localidades rurales}

En los últimos tres lustros, el estado de Veracruz ha logrado un mejoramiento sostenido de las coberturas de agua y alcantarillado en las zonas rurales, sin embargo, aún se encuentran por debajo de las medias nacionales. En el año 2000 la cobertura de la población con agua era de $44.3 \%$, y para 2015 de $73.5 \%$ (CAEV, 2016b).

La atención en las zonas rurales de Veracruz se dio a partir de 1991 cuando el estado padeció la epidemia del cólera: en 14 municipios se presentaron 251 casos (Alvarado, Antigua, Boca del Río, Cotaxtla, Ignacio de la Llave, Jamapa, Manlio F. Altamirano, Medellín, Paso de Ovejas, Puente Nacional, Soledad de Doblado, Tlalixcoyan, Úrsulo Galván y Veracruz.); en 1992 hubo 422 casos, y en 1993 se presentaron 944, dando un total de 1626 casos de brote de cólera. Los municipios con mayor incidencia fueron Alvarado, Veracruz y Boca del Río (Campos, 1994, p. 30). Y recientemente, en 2013, la Organización Mundial de la Salud (OMS) notificó sobre diez casos de brote de Vibrio cholerae 01 Ogawa, de los primeros desde la epidemia de 


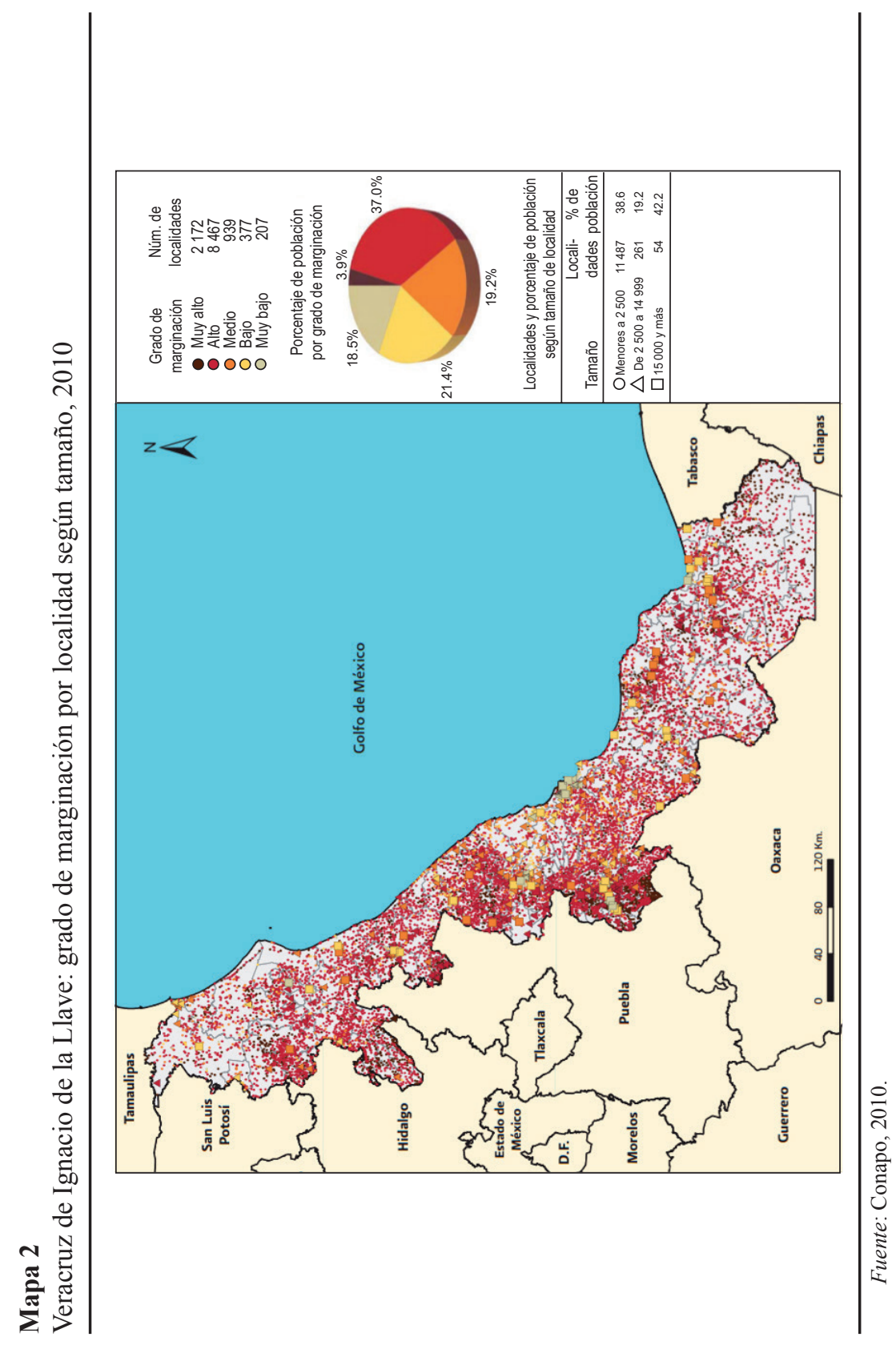


1991 a 2001 (OMS, 2013). Estas enfermedades están asociadas a la calidad del agua, que ha sido un problema persistente en la entidad.

Ante tal emergencia, en 1991 surgió el Programa de Agua Limpia (PAL) como una intervención federal para apoyar a los municipios en la prestación del servicio de agua potable. En 1996 inició con un incipiente esquema federalizado, sin reglas de operación, pues se buscaba que las transferencias llegaran en el menor plazo posible. Posteriormente, en 1998, la ejecución de las acciones y la contratación se transfirieron a las entonces Gerencias Regionales (Conagua, 2012b). Durante la década de los noventa los recursos fluyeron con mayor dinamismo, y en la entidad la CAEV los ejecutaba por medio de sus oficinas desconcentradas, posteriormente descentralizadas. En ese entonces se llevaba un control sistemático de las acciones de desinfección llevadas a cabo en las localidades, así como de las acciones de fortalecimiento de la participación social en los patronatos de agua y juntas de agua en el medio rural (CAEV, 2016).

Actualmente el estado de Veracruz presenta coberturas de agua potable y alcantarillado por debajo de la media nacional. Para el país, la media de agua potable es de $92.4 \%$ y la de alcantarillado es de $91.0 \%$ (Conagua, 2015). En el mismo periodo, Veracruz registró $84.1 \%$ de cobertura de agua potable (6 576018 habitantes contaban con el servicio de agua potable) y $85.4 \%$ de alcantarillado (6 678180 habitantes). Para 2014 existían 1244161 habitantes sin el servicio de agua potable (15.9\%) y 1141998 habitantes no tenían el servicio de alcantarillado (14.6\%) (Conagua, 2015).

La Gráfica 1 muestra las coberturas del servicio desagregadas por localidades rurales menores a 2499 habitantes, localidades urbanas de 2500 a 9999 habitantes, y ciudades de 10000 habitantes y más. La cobertura de agua en zonas rurales tiene una tendencia positiva, pero la brecha entre ésta y las de las zonas urbanas y ciudades es considerable: para 2015 las ciudades registraron una cobertura de $94.0 \%$, mientras que en las localidades rurales fue de $73.5 \%$ (cifra muy inferior al promedio nacional de $82.9 \%$ para las zonas rurales en 2014).

El avance en la cobertura de alcantarillado en las zonas rurales de Veracruz ha sido importante: en tan sólo 15 años mejoró de una cobertura de $35.9 \%$ en el año 2000, a $73.9 \%$ en 2015 , ubicándose por arriba de la cobertura media nacional de alcantarillado para las zonas rurales, que era $72.8 \%$ para diciembre de 2014 (Conagua, 2015) (véase la Gráfica 2).

En la década de los noventa, en Veracruz se implementó una política para la promoción y consolidación de los patronatos de agua en las localidades rurales, con fundamento en su marco normativo (Ley número $72 \mathrm{de}$ Agua y Saneamiento para el Estado de Veracruz-Llave). Si bien la Comisión 


\section{Gráfica 1}

Porcentaje de cobertura de agua potable total, urbana y rural de Veracruz, 1990-2015

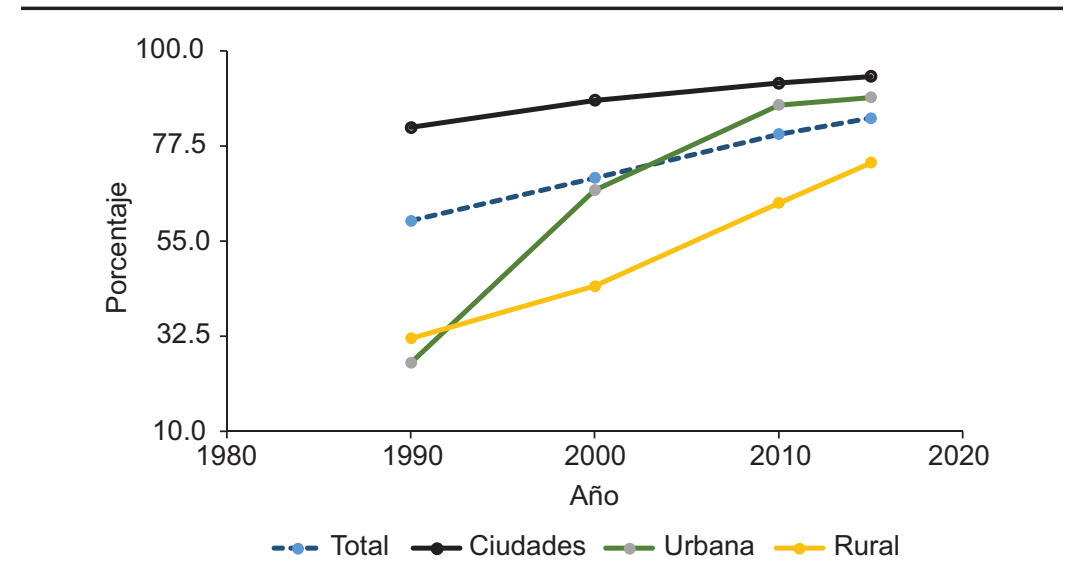

Fuente: Elaboración propia con base en Conagua, 2015; INEGI, 1990, y con datos proporcionados por la CAEV.

\section{Gráfica 2}

Porcentaje de cobertura de alcantarillado total, ciudades, urbana y rural de Veracruz, 1990-2015

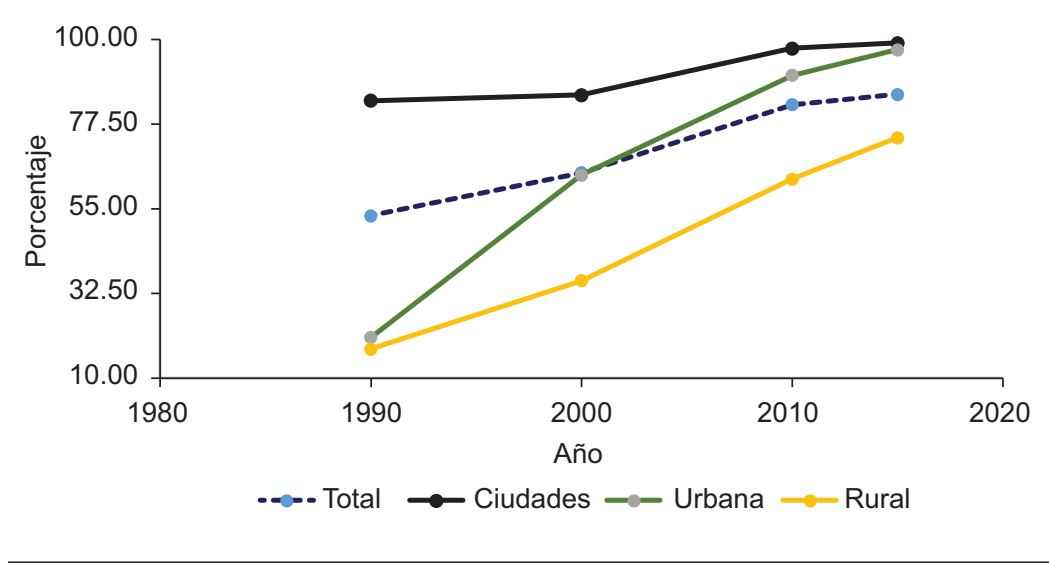

Fuente: Elaboración propia con datos de la CAEV (varios años) y Conagua, 2015.

Estudios Demográficos y Urbanos, vol. 33, núm. 2 (98), 2018, pp. 469-503 ISSN 0186-7210; e ISSN 2448-6515; doi: http://dx.doi.org/10.24201/edu.v33i2.1764 
de Agua del Estado de Veracruz (CAEV) tenía conocimiento de la ubicación y características de los patronatos en la entidad, la entidad transitó a un nuevo marco normativo que modificó el funcionamiento de la administración del agua e impactó la gestión en el medio rural (Ley 21 de Aguas del Estado de Veracruz-Llave). La regionalización de la CAEV en la década de los noventa contribuyó positivamente a la mejora de las coberturas de agua potable y alcantarillado en las localidades rurales, haciendo más efectiva y eficiente la ejecución de los recursos del Programa de Agua Limpia, por la capacidad institucional y de recursos que el gobierno estatal tenía en comparación con las posibilidades de los municipios.

A poco más de dos décadas de la reforma del artículo 115 constitucional, se identificó que en el país, de los 2517 organismos operadores de agua potable y saneamiento constituidos en el año 2009, únicamente $48.2 \%$ atendía a localidades rurales y urbanas, y $41.8 \%$ sólo atendía a localidades urbanas. En 2011, del total de las cabeceras municipales del estado, 78.18\% contaba con agua potable y/o alcantarillado, mientras que el resto de los municipios, en promedio tenía una cobertura de 44.11\%; en 2013 las coberturas eran de 81.04 y $43.03 \%$, respectivamente (INEGI, 2011; 2013).

La municipalización de los servicios de agua potable y saneamiento se llevó a cabo en un contexto donde existían condiciones territoriales de desigualdad. Tan sólo en el periodo en que la CAEV entregaba a manos de los municipios los sistemas de agua, el Índice de Desarrollo Municipal Básico (IDMB) 2005 mostraba que Veracruz era el tercer estado con municipios menos desarrollados, después de Oaxaca y Guerrero; es decir, era la tercera entidad con menores índices de desarrollo social, económico, ambiental, de servicios, e institucional. Por tal motivo, no es extraño que, a pesar de que el marco normativo obligue a los municipios a proveer de los servicios de agua potable y saneamiento, "en los hechos vemos que estas funciones las ejerce directamente la autoridad estatal, por la falta de capacidad local" (Domínguez, 2010, p. 330). Para constatarlo, basta con revisar el porcentaje de provisión de agua por organismo operador: la CAEV (43\%), el organismo operacional municipal (31\%), el organismo operador paramunicipal (14\%), los sistemas rurales y las juntas de agua y operación (9\%), las Comisiones Regionales (3\%), y el organismo operacional intermunicipal (0\%) (CAEV, 2003, citado en Domínguez, 2010, p. 331). En 2005, alrededor de la mitad de los municipios habían cedido su competencia a la CAEV, de tal forma que sólo los grandes y con mayores capacidades constituyeron un organismo operador municipal.

El estado, a través de la CAEV, tiene un papel relevante en la administración del agua potable y saneamiento en las zonas rurales. En la zona 


\section{Gráfica 3}

Relación del número de sistemas rurales administrados por las oficinas operadoras de la CAEV, 2016

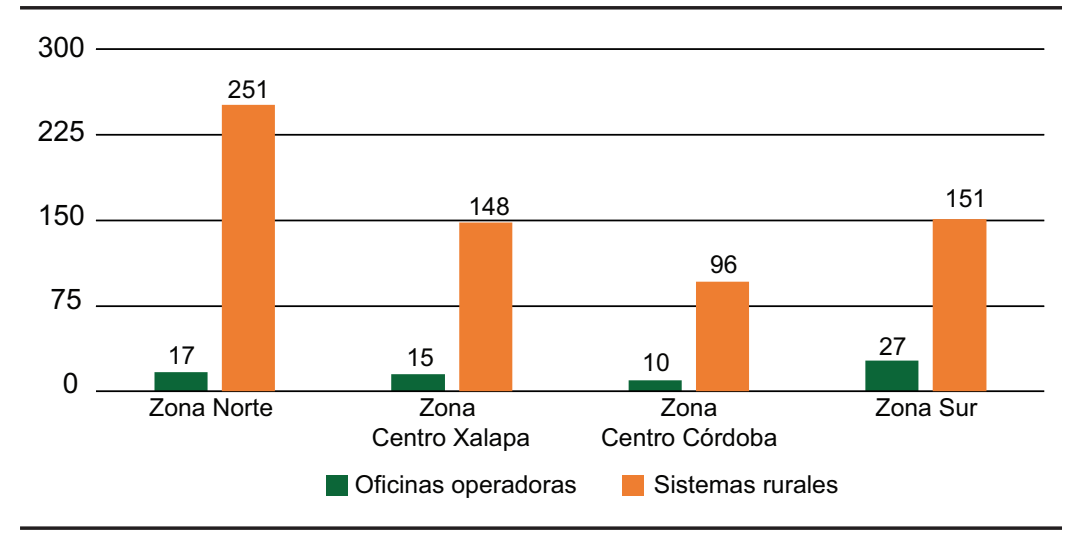

Fuente: Inventario CAEV, 2016a.

Norte, por cada 14.7 sistemas rurales hay una oficina de la CAEV; en la zona Centro Xalapa la relación es de 9.8; en la zona Centro Córdoba es de 9.6; y en la Sur, de 5.5 sistemas rurales por cada oficina operadora. Para 2016 se reportan en total 646 sistemas rurales administrados por la Comisión (véase la Gráfica 3 y los Mapas 3, 4, 5 y 6).

En 2003, de los 229 sistemas de agua administrados por las Comisiones Municipales de Agua, alrededor de $61 \%$ eran sistemas de 381 tomas de agua o más, y $39 \%$ sistemas menores de 380 tomas (CAEV, 2003). Los sistemas operados por los ayuntamientos sumaban 461, de los cuales $19 \%$ tenían más de 381 tomas, mientras que $81 \%$ eran sistemas con menos de 380 tomas de agua; las localidades rurales en su mayoría tienen menos de 380 tomas, por lo que difícilmente entran en la cobertura formal de agua y alcantarillado.

\section{Las OCSAS o patronatos en Veracruz}

La existencia de patronatos de agua en Veracruz data de la década de los cincuenta. En un estudio de campo en la Zona Metropolitana de Xalapa realizado en 2012, se encontró un comité de agua en funcionamiento (con 850 tomas registradas en 2003), que inició gestiones desde la década de los treinta, hace aproximadamente 85 años; en 1950 se constituyó como consejo, conformándose en 1970 como asociación civil (Castillo, 2012). 


\section{Mapa 3}

Zona Norte: número de sistemas rurales administrados por las oficinas operadoras de la CAEV, 2016

\begin{tabular}{clc}
\hline Núm. & $\begin{array}{c}\text { Oficina } \\
\text { operadora }\end{array}$ & $\begin{array}{c}\text { Sistemas } \\
\text { rurales }\end{array}$ \\
\hline 1 & Pánuco & 42 \\
2 & Pueblo Viejo & 3 \\
3 & El Higo & 0 \\
4 & Tempoal & 11 \\
5 & Tantoyuca & 47 \\
6 & Platón Sánchez & 19 \\
7 & Naranjos & 1 \\
8 & Cerro Azul & 6 \\
9 & Tepetzintla & 4 \\
10 & Chicontepec & 23 \\
11 & Álamo Temapache & 7 \\
12 & Tuxpan & 16 \\
13 & Cazones de Herrera & 4 \\
14 & Poza Rica & 0 \\
15 & Coatzintla & 29 \\
16 & Papantla & 31 \\
17 & Gutiérrez Zamora & 8 \\
\hline & Total & 251 \\
\hline
\end{tabular}

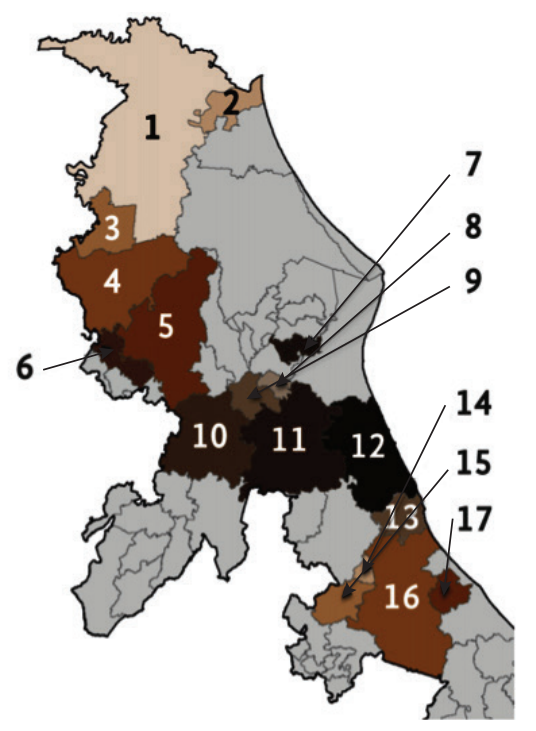

Fuente: Inventario CAEV, 2016a.

Actualmente en la entidad operan por su cuenta 1520 sistemas de agua potable; ${ }^{2}$ de éstos, en 2003 había 1425 patronatos registrados, que tenían a su cargo 149291 tomas de agua. ${ }^{3}$ De los 212 municipios del estado, los patronatos de agua tenían presencia en 162 de ellos; es decir, en $76.4 \%$ de los municipios de Veracruz existía gestión comunitaria de agua por medio de los patronatos; de éstos, aproximadamente noventa se construyeron como sistemas múltiples, es decir, con infraestructura que puede recorrer distintas localidades, incluso diferentes municipios (CAEV, 2003).

En 2003, 8 municipios tenían entre 25 y 38 patronatos de agua; $20 \mathrm{mu}-$ nicipios, entre 16 y 24 patronatos; 38 municipios de 9 a 15 patronatos; 55 municipios, de 3 a 8 ; y 41 municipios entre 1 y 2 patronatos de agua (véase el Mapa 7). da en 2016.

2 Esta cifra se obtuvo a partir de una entrevista con un funcionario de la CAEV, realiza-

3 Datos obtenidos de bases de datos proporcionados por un funcionario de la CAEV. 


\section{Mapa 4}

Zona Centro Xalapa: número de sistemas rurales administrados por las oficinas operadoras de la CAEV, 2016

\begin{tabular}{clc}
\hline Núm. & $\begin{array}{c}\text { Oficina } \\
\text { operadora }\end{array}$ & $\begin{array}{c}\text { Sistemas } \\
\text { rurales }\end{array}$ \\
\hline 1 & Tlapacoyan & 4 \\
2 & Jalacingo & 1 \\
3 & Altotonga & 9 \\
4 & Misantla & 4 \\
5 & Vega de Alatorre & 4 \\
6 & Emilio Carranza & 11 \\
7 & Perote & 8 \\
8 & Las Vigas de Ramírez & 5 \\
9 & Xico & 2 \\
10 & Chichicaxtle & 15 \\
11 & Tlaltetela & 4 \\
12 & Soledad de Doblado & 13 \\
13 & Martínez de la Torre & 41 \\
14 & Piedras Negras & 19 \\
15 & Alvarado & 8 \\
\hline & Total & 148 \\
\hline
\end{tabular}

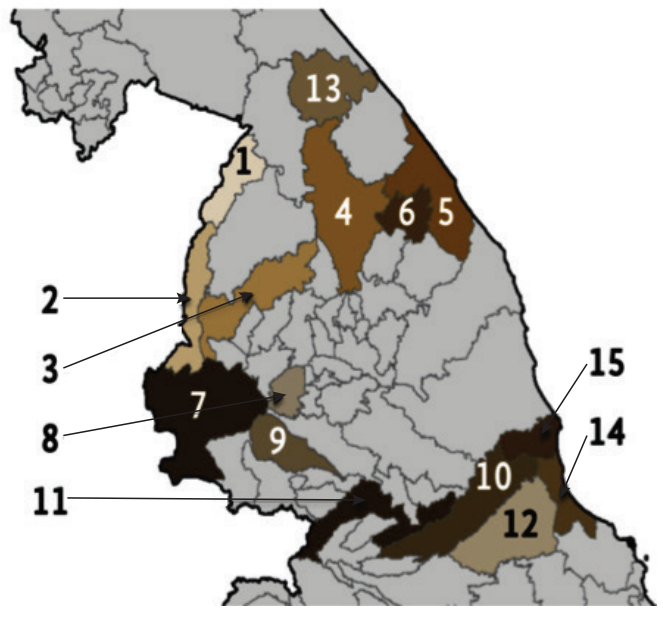

Fuente: Inventario CAEV, 2016a.

En cuanto a la fuente de los patronatos para el abastecimiento de agua, $65 \%$ (932), son manantiales, $18 \%$ (257) se abastecen de pozos, $3 \%$ (43) de río, y $0.56 \%$ (8) de laguna; otras fuentes menos frecuentes son de las presas y los arroyos, entre otros (CAEV, 2003). El $93 \%$ (1 325) de los patronatos de agua tienen tomas en un rango de 1 a 286 tomas, $5 \%$ (75) de los patronatos administran entre 287 y 572 tomas, y el resto tiene más de 573 tomas de agua. Cabe mencionar que cuatro patronatos tienen entre $1145 \mathrm{y}$ 1430 tomas (CAEV, 2003). En cuanto al flujo de agua que manejan los patronatos, 1200 de ellos disponen de 0 a 4.9 litros por segundo, los cuales representan $84 \%$ del total; 153 patronatos mantienen más de 10 litros por segundo, y tan sólo cinco patronatos tienen asignado de 40 a 99.9 litros por segundo (CAEV, 2003).

La organización comunitaria para la construcción, la operación y el mantenimiento de los sistemas ha tenido modificaciones en el marco normativo del estado; en ocasiones las reconoce explícitamente, y otras veces no; sin embargo, su presencia en la provisión de agua en las zonas rurales es consistente, $\mathrm{y}$ en algunos casos sus actividades han permanecido por más de cinco décadas. 


\section{Mapa 5}

Zona Centro Córdoba: número de sistemas rurales administrados por las oficinas operadoras de la CAEV, 2016

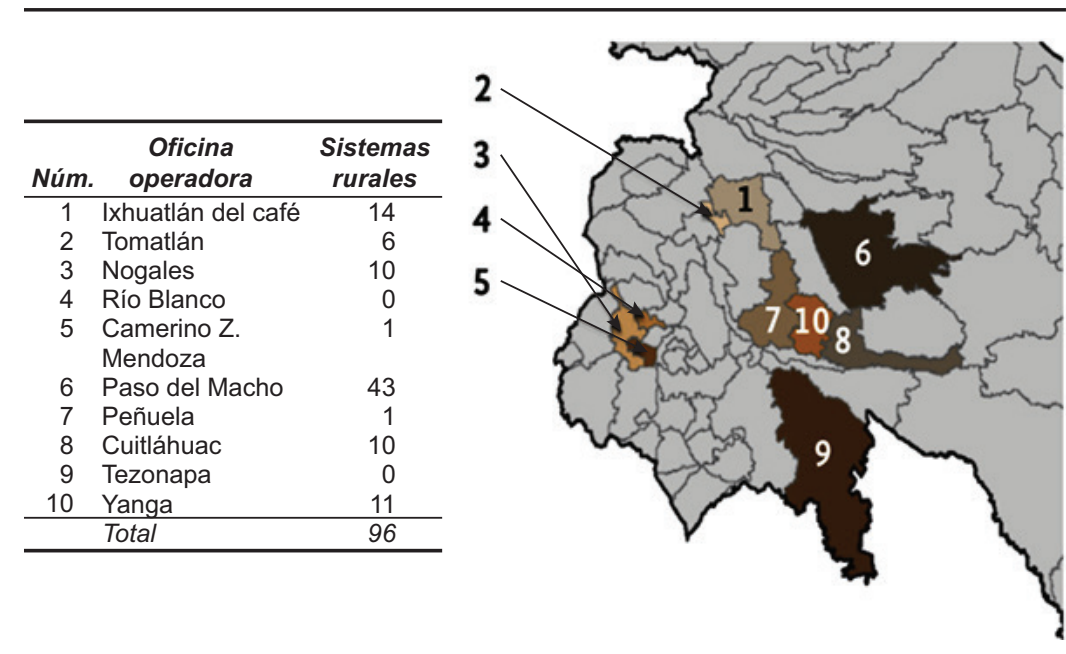

Fuente: Inventario CAEV, 2016a.

Desde la década de los cincuenta, en las zonas rurales las organizaciones comunitarias han aprendido a gestionar, administrar y operar los sistemas hídricos, y han incorporado a sus usos y costumbres algunas formas de organización que, con sus limitaciones, han funcionado para la provisión básica del líquido. La organización en patronatos o comités de agua les ha resultado un medio efectivo para obtener el mínimo básico.

El PAL permitió llevar un mejor control de la calidad de agua que suministraban los patronatos a las localidades rurales, y se acostumbró su cloración. Este cambio cultural fue posible en un marco institucional específico, la ya desconcentrada y posteriormente descentralizada CAEV permitió tener una presencia regional de la autoridad hídrica del estado, lo cual permitió una mejor supervisión y mayor capacidad de respuesta en las zonas rurales.

La posterior reestructuración de la administración pública estatal del agua, y en particular su retraimiento para dar paso a la municipalización de los servicios, frenó la continuidad de la política estatal que coordinaba las acciones para atender las zonas rurales. La gran mayoría de los municipios no se encontraban preparados para atender las necesidades de la población rural: no conocían la dinámica ni los términos adecuados para darle conti- 


\section{Mapa 6}

Zona Sur: número de sistemas rurales administrados por las oficinas operadoras de la CAEV, 2016

\begin{tabular}{rlr}
\hline Núm. & \multicolumn{1}{c}{$\begin{array}{c}\text { Oficina } \\
\text { operadora }\end{array}$} & $\begin{array}{c}\text { Sistemas } \\
\text { rurales }\end{array}$ \\
\hline 1 & Cosamaloapan & 29 \\
2 & Cd. Alemán & 6 \\
3 & Otatitlán & 2 \\
4 & Tlacotalpan & 4 \\
5 & Saltabarranca & 1 \\
6 & Carlos A. Carrillo & 3 \\
7 & Chacaltianguis & 3 \\
8 & Ángel R. Cabada & 5 \\
9 & Villa Azueta & 5 \\
10 & Isla & 1 \\
11 & Santiago Tuxtla & 0 \\
12 & Catemaco & 0 \\
13 & Juan D. Covarrubias & 14 \\
14 & Juan Rodríguez Clara & 5 \\
15 & Playa Vicente & 10 \\
16 & Tres Valles & 16 \\
17 & Acayucan & 9 \\
18 & Chinameca & 2 \\
19 & Cosoleacaque & 29 \\
20 & Coatzacoalcos & 3 \\
21 & Nanchital & 0 \\
22 & Ixhuatlán del Sureste & 0 \\
23 & Agua Dulce & 0 \\
24 & Minatitlán & 2 \\
25 & Sayula & 1 \\
26 & Jesús Carranza & 1 \\
27 & Las Choapas & 0 \\
\hline & Total & 151 \\
\hline & &
\end{tabular}

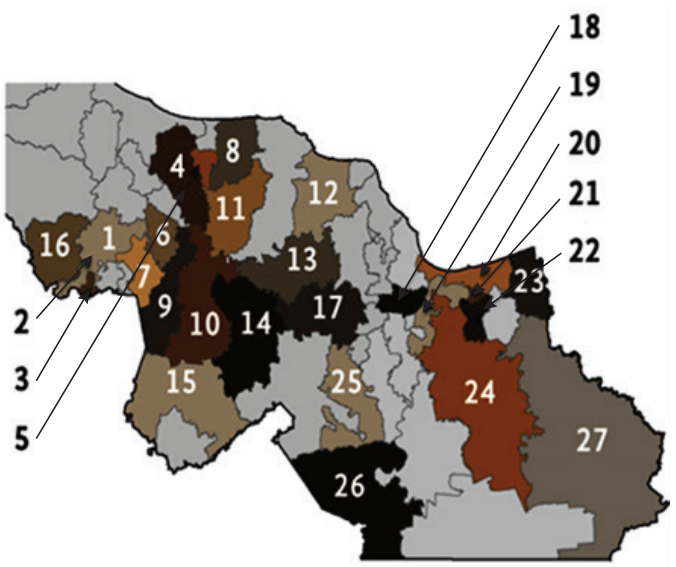

Fuente: Inventario CAEV, 2016a.

nuidad a una relación de colaboración que las organizaciones comunitarias habían tenido a lo largo de la historia, tanto con la federación como, en su momento, con el estado.

La Ley 21 de Aguas para el Estado de Veracruz-Llave (publicada el 29 de junio de 2001 en la Gaceta Oficial) y su Reglamento (publicado el 28 de octubre de 2002 en la Gaceta Oficial) no incluyen los principios básicos que deben regir la organización comunitaria, ya sean las juntas de agua o los patronatos existentes, ni para los comités de agua de reciente creación. Este marco normativo tiene vacíos, pues omite lo que a lo largo de cinco décadas se ha venido construyendo en las zonas rurales. La reglamentación municipal para los servicios de agua potable y saneamiento en Veracruz es insuficiente, prácticamente inexistente, puesto que sólo se encontró un reglamento municipal, el de Xalapa, que hacía mención de los patronatos de agua (uno de los nombres de las OCSAS en Veracruz).

Probablemente el artículo 58 del reglamento interior de la Comisión Municipal de Xalapa es un ejemplo del desconocimiento de la dinámica de 


\section{Mapa 7}

Presencia de patronatos de agua en los municipios del estado de Veracruz

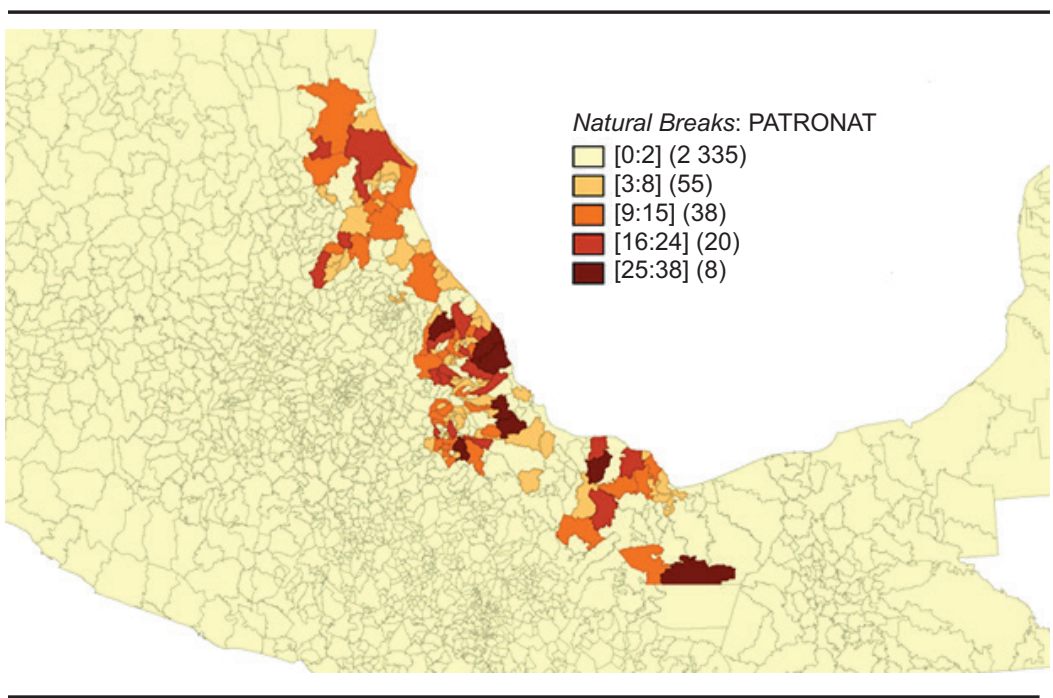

Fuente: Elaboración propia con datos proporcionado por la CAEV, 2003.

los patronatos de agua en las zonas rurales, pues éstos están fuera de la lógica de la elección de jefes de manzana; en general, los patronatos se han regido por asambleas generales de usuarios, las cuales han tenido aceptación como medio para la toma de decisiones y la elección de la directiva del patronato o comité. Por ello, es posible que el reglamento funcione para la organización comunitaria en las zonas urbanas, pero no así en las localidades rurales.

Si bien el financiamiento del Prossapys fue determinante para ampliar la cobertura, no se observó que a la par de dicha política se llevaran a cabo acciones para atender las necesidades de los patronatos y los comités de agua previamente constituidos, pues de los aproximadamente 2000 patronatos constituidos, la CAEV sólo administra una cuarta parte de ellos, mientras que el resto opera prácticamente desde la autogestión y con autonomía en la toma de decisiones. Funcionan sin tener un programa de capacitación en asuntos básicos como el mantenimiento mínimo de la infraestructura, por lo que son insostenibles.

Los organismos operadores municipales en la entidad son prácticamente de reciente creación, se constituyeron en las principales ciudades del estado y atienden predominantemente a las localidades más urbanizadas, y en gran medida tienen dificultades para proveer de agua a las zonas rurales. Este 
problema no sólo deriva de que carecen de recursos económicos y humanos suficientes, sino de que tradicionalmente las localidades rurales se han organizado para autosuministrarse del líquido, por lo que los municipios han desistido de intervenir en dichas organizaciones. Sin embargo, la falta de seguimiento, capacitación y supervisión de los sistemas rurales de agua puede devenir, como ya ocurre, en el inadecuado mantenimiento de los sistemas y, por lo tanto, en la necesidad pronta de rehabilitarlos con recursos externos, ya que los sistemas rurales en su mayoría no recaudan lo suficiente para rehabilitar la red, mucho menos para su ampliación.

A pesar de los avances de la cobertura hídrica en las zonas rurales, cifras de 2015 demuestran que $26.5 \%$ de la población rural en Veracruz carece del líquido, es decir, aproximadamente 768500 personas no tienen acceso a agua para el consumo humano.

\section{Resultado del trabajo de campo: OCSAS en la Zona Metropolitana de Xalapa}

En el Cuadro 1 se muestra una síntesis de los grupos focales y de las entrevistas realizadas a las OCSAS o comités de agua asentados en la Zona Metropolitana de Xalapa, a quienes se les interrogó en relación con su funcionamiento, organización y vínculos con otras organizaciones comunitarias del ramo, para conocer el grado de su organización social.

\section{Hallazgos}

A partir de las entrevistas realizadas a funcionarios públicos, estatales y municipales, así como de la información obtenida en los grupos focales, se confirma que existe una organización comunitaria del agua con rasgos similares a lo encontrado en otras entidades nacionales (Soares, 2007; Gutiérrez et al., 2013; López, Martínez y Palerm, 2013; Díaz Santos, 2014; Galindo Escamilla y Palerm, 2007; Sandoval, 2011; Casas, 2015; Programa de las Naciones Unidas para el Desarrollo, 2011; Escobar, 2015) y en la región latinoamericana (CLOCSAS, 2012; Zambrana, 2017). Es decir, comités de agua que funcionan con una directiva - presidente, secretario y tesorero- con puestos honoríficos, y con una Asamblea General de Usuarios donde se toman las decisiones de forma deliberativa; asimismo, buena parte de los integrantes de dichos comités son personas sin estudios ni preparación técnica, con algunas excepciones. 


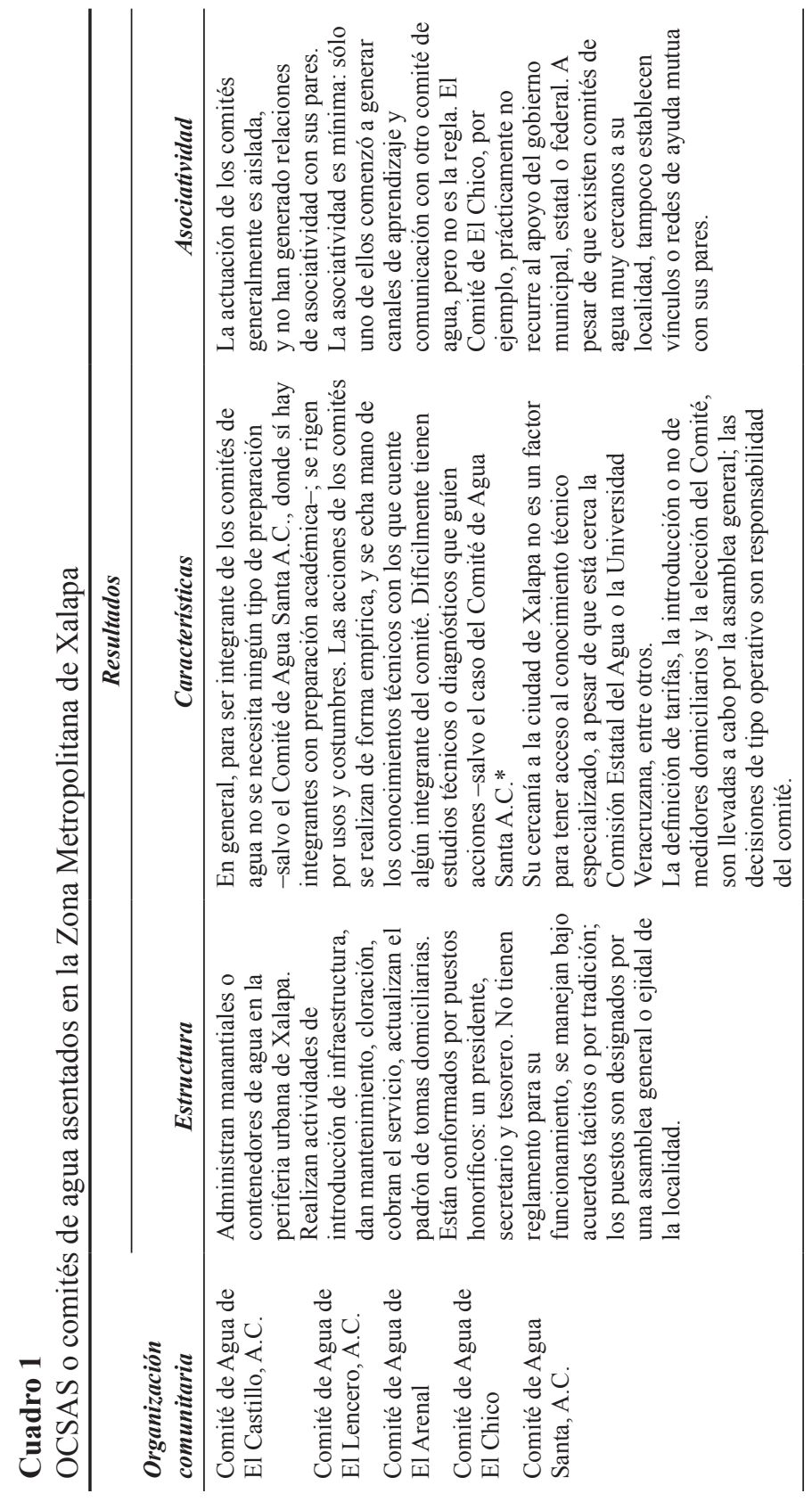




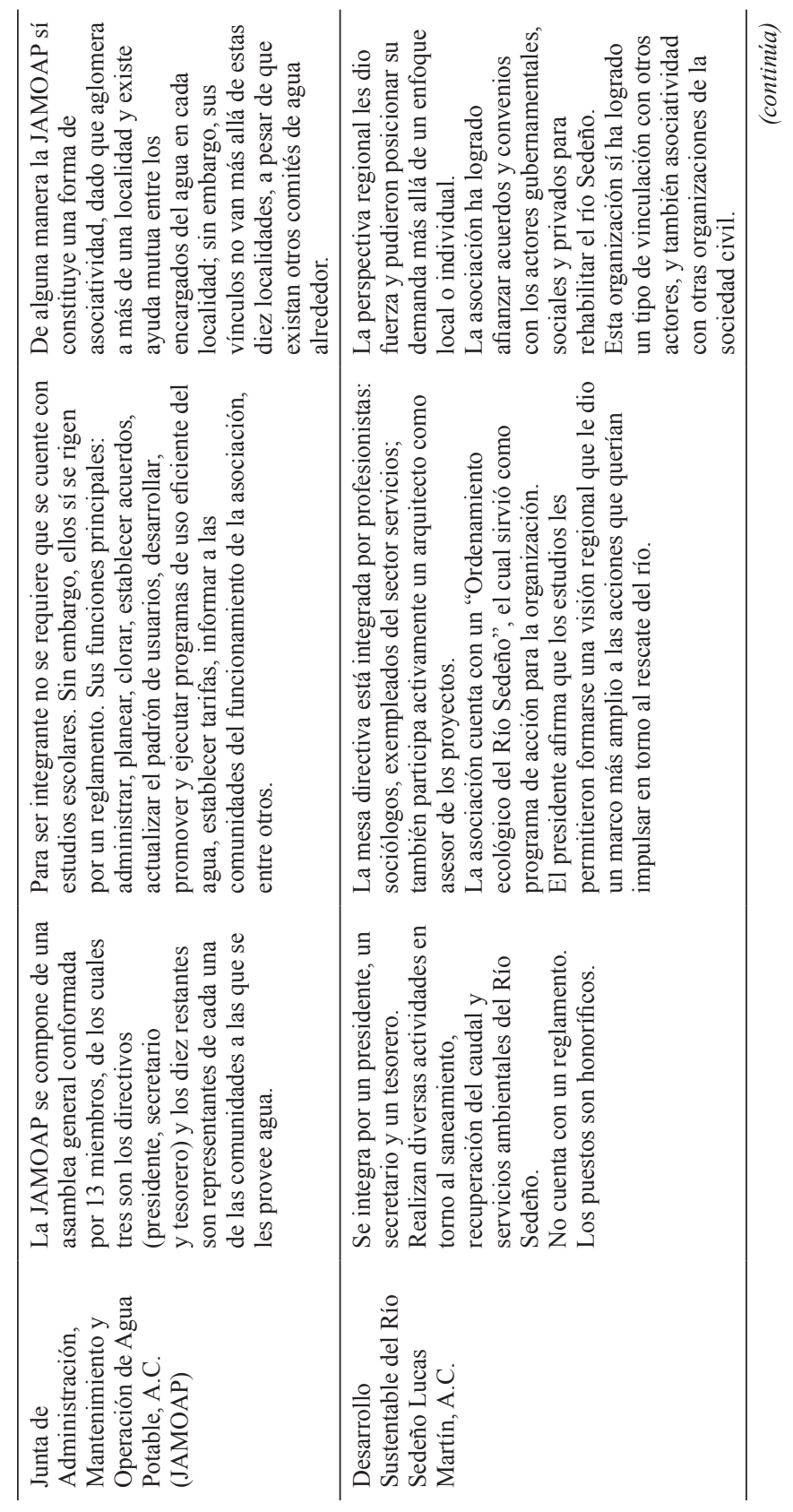




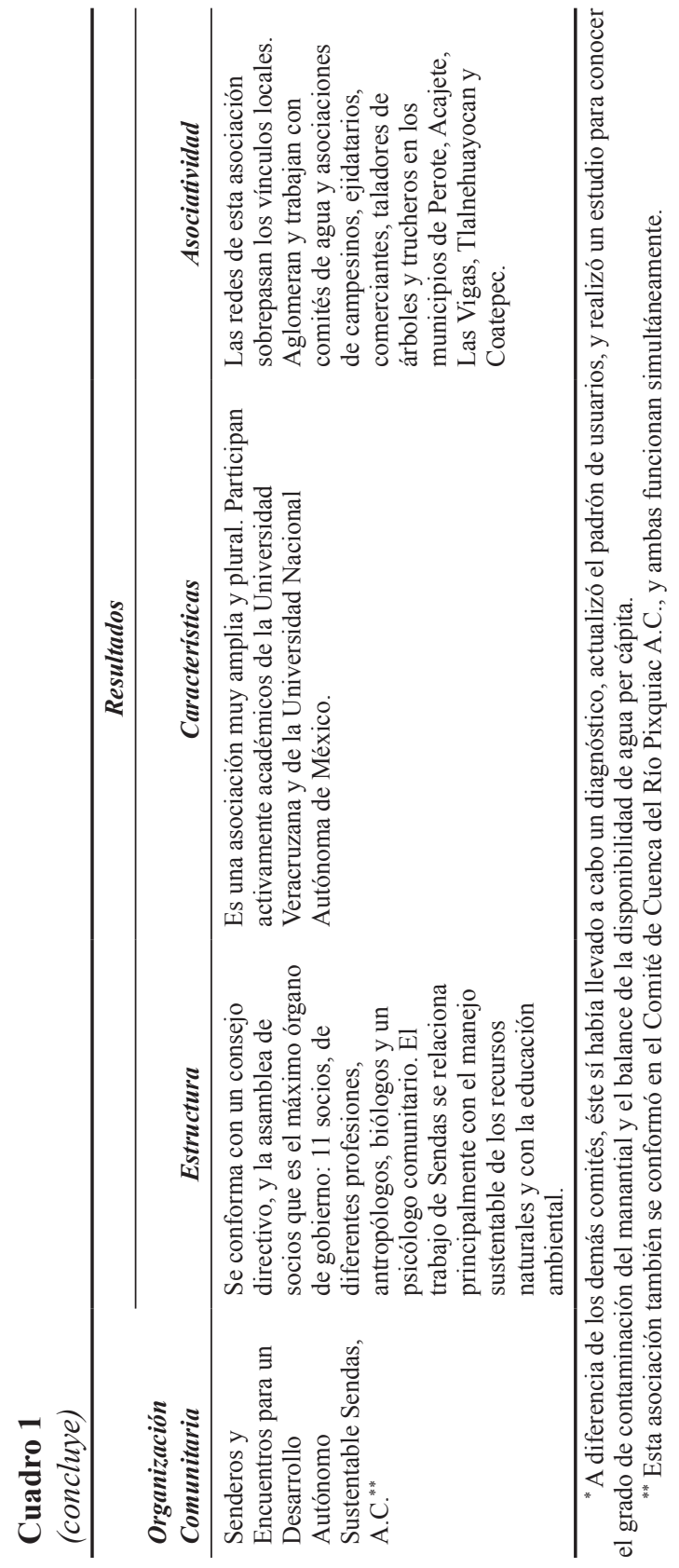


Inicialmente se había considerado que la dispersión de las localidades era un factor para que no existiera asociatividad entre las OCSAS. Sin embargo, en la Zona Metropolitana de Xalapa hay localidades que no están aisladas y que se encuentran en la periferia urbana o en zonas conurbadas, y a pesar de que en ellas existían comités de agua muy próximos, no se crearon vínculos que derivaran en una asociatividad; de hecho, no era de su interés. Este trabajo aislado que realizan dichas OCSAS puede comprenderse en cierta medida porque su fuente de abastecimiento predominante son los manantiales, lo que les facilita un manejo más independiente.

Asimismo, su proximidad a la capital del estado de Veracruz tampoco ha sido un factor determinante para que las OCSAS tengan mayores vínculos con la CAEV o con organizaciones de la sociedad civil, con la excepción de los comités apoyados por alguna de ellas. Es decir, la cercanía a institutos de investigación o universidades no necesariamente se traduce en un manejo comunitario del agua con mayor conocimiento técnico.

La asociatividad se observó a partir de dos procesos distintos: por un lado, el del caso de la JAMOAP, A.C., y por otro, el de las asociaciones civiles Desarrollo Sustentable del Río Sedeño Lucas Martín, A.C. y Sendas, A.C. El primero de ellos es el resultado de la política estatal que llevaba a cabo la CAEV, enmarcada en la Ley núm. 72, artículo 12, donde se reconocía como prestadores del servicio a los Patronatos y Juntas de Administración, Mantenimiento y Operación de Agua Potable (pero la Ley núm. 21 dejó de reconocerlas, con el argumento de que hasta que no se expidiera el reglamento, seguirán funcionando como lo habían estado haciendo). Sin embargo, esta asociatividad no se ha impulsado más desde que se fundó dicha organización, a pesar de que existen otras OCSAS muy próximas a ellos.

En el caso de las asociaciones civiles en torno al agua, la asociatividad se generó a partir del interés de la sociedad civil, predominantemente de académicos que llevaron sus esfuerzos a generar un espacio de gobernanza para la gestión y la sustentabilidad de la cuenca, mediante metodologías participativas para la generación de confianza, y también haciendo uso de las vías formales de participación que los marcos regulatorios federales, estatales y municipales permiten.

A partir del análisis de la política para proveer de agua a las localidades rurales del estado de Veracruz, se puede afirmar que a lo largo del tiempo ha habido avances en la construcción de sistemas hídricos y en la formación de organizaciones sociales en torno a la provisión del servicio, lo que ha repercutido en el aumento de la cobertura del líquido en el medio rural. No obs- 
tante, como toda política pública, ésta es mejorable. El reconocimiento explícito normativo puede favorecer el fortalecimiento de la gestión comunitaria como una vía que permita aumentar la cobertura de agua en las localidades dispersas, mantener los sistemas y, en el mediano plazo -si se integra la capacitación técnica y administrativa-, puede ser la base para la sostenibilidad de los sistemas. Lo que hace falta para su fortalecimiento es una decisión política federal y estatal.

\section{Bibliografía}

Aguilar, A. (2011). Gestión comunitaria de los servicios de agua y saneamiento: su posible aplicación en México. México: CEPAL.

Barlow, M. (2007). Blue covenant: The global water crisis and the coming battle for the right to water. Toronto: McClelland \& Stewart.

Bernal, A., Rivas, L. y Peña, P. (2014). Propuesta de un modelo de cogestión para los pequeños abastos comunitarios de agua en Colombia. Perfiles Latinoamericanos, 22(43), 159-184. Recuperado de http://www.scielo.org.mx/scielo. php?script=sci_arttext\&pid=S0188-76532014000100007\&lng=es\&tlng=es

CAEV. (2003). Inventario de sistemas (formato en Excel). Xalapa, Ver.: Comisión del Agua del Estado de Veracruz.

CAEV. (2016). Entrevista realizada a un funcionario de la Unidad de Planeación de la Comisión del Agua del Estado de Veracruz / Entrevistador: Judith Domínguez. Xalapa, Veracruz, 19 de agosto.

CAEV. (2016a). Inventario de oficinas operadoras. Sistemas urbanos y sistemas rurales. Xalapa, Ver.: Comisión del Agua del Estado de Veracruz, Subdirección de Operación y Mantenimiento.

CAEV. (2016b). Comisión del Agua del Estado de Veracruz 2011-2016. Xalapa, Ver.: CAEV.

Campos, M. (1994). Cólera en Veracruz (tesis para obtener el título de médico cirujano). Universidad Veracruzana.

Cárdenas, J. E. (2009). Dilemas de lo colectivo: instituciones, pobreza y cooperación en el manejo local de los recursos de uso común. Bogotá, Colombia: Universidad de los Andes. Recuperado de http://www.conectas.org/arquivos-site/Cardenas\%20Dilemas\%20de\%2010\%20Colectivo\%20Cap_1.pdf

Carrasco, P. y Luna, R. (2014). Fortaleciendo capacidades para un mejor acceso al agua potable y al saneamiento (Informe final). Quito, Ecuador: Programa Unificado de Fortalecimiento de Capacidades para OCSAS. Recuperado de http:// www.care.org.ec/wp-content/uploads/2014/06/Libro\%20Fortaleciendo\%20 Capacidades\%2011-04-2014.pdf

Casas, Cervantes, A. F. (2015). La gestión comunitaria del agua y su relación con las políticas públicas municipales. El caso del manantial de Patamburapio en el 
estado de Michoacán, 2009-2014. Intersticios Sociales, 10. Recuperado de http:// www.scielo.org.mx/pdf/ins/n10/n10a6.pdf

Castillo Pérez, E. (2012). Elementos para la vinculación de las organizaciones de la sociedad civil: hacia una gobernanza del agua en la Zona Metropolitana de Xalapa, Veracruz (tesis de maestría, El Colegio de la Frontera Norte Tijuana, B.C.). Recuperado de http://www.colef.mx/posgrado/wp-content/ uploads/2014/03/TESIS-Castillo-P\%C3\%A9rez-Erandi-Amor.pdf

Castro, J. E. (2006). La lucha por la democratización de la gestión del agua y sus servicios [sección Aqua, vita et cultura]. Legatus. Recuperado de http://www. legatus.es/pdf/esp/agua/joseesteban.pdf

Cenagrap. (2011). Yakukamay, alianza público-comunitaria: un modelo de gestión del agua. La experiencia desde el Cenagrap. Ecuador: Centro de Apoyo a la Gestión Rural del Agua Potable. Recuperado de https://issuu.com/protosngo/ docs/yakukamay_sistematizacion_cenagrap_

CLOCSAS. (2012). La asociatividad como estrategia en la gestión comunitaria del agua en Latinoamérica. Confederación Latinoamericana de Organizaciones Comunitarias de Servicios de Agua y Saneamiento. Recuperado de https://drive. google.com/file/d/0B4IheHgOxmYuSG93VkF3ZFFNODQ/view?pli=1

Conagua. (2009). Situación del Subsector de Agua Potable, Alcantarillado y Saneamiento. México: Semarnat, Comisión Nacional del Agua. Recuperado de https:// www.gob.mx/cms/uploads/attachment/file/108993/DSAPAS_2009.pdf

Conagua. (2011). Situación del Subsector de Agua Potable, Alcantarillado y Saneamiento. México: Semarnat, Comisión Nacional del Agua. Recuperado de https:// www.gob.mx/cms/uploads/attachment/file/108995/DSAPAS_2011.pdf

Conagua. (2012). Situación del Subsector de Agua Potable, Alcantarillado y Saneamiento. México: Semarnat, Comisión Nacional del Agua. Recuperado de https:// www.gob.mx/cms/uploads/attachment/file/108996/DSAPAS_2012.pdf

Conagua. (2012a). Sistema de Información Nacional del Agua. México: Semarnat, Comisión Nacional del Agua.

Conagua. (2012b). Memoria documental del Programa Agua Limpia S047 2007-2012. México: Semarnat, Comisión Nacional del Agua.

Conagua (2013). Situación del Subsector de Agua Potable, Alcantarillado y Saneamiento. México: Semarnat, Comisión Nacional del Agua. Recuperado de https:// www.gob.mx/cms/uploads/attachment/file/108997/DSAPAS_2013.pdf

Conagua. (2014). Situación del Subsector de Agua Potable, Alcantarillado y Saneamiento. México: Semarnat, Comisión Nacional del Agua. Recuperado de https:// agua.org.mx/wp-content/uploads/2015/09/situacion-del-subsector-agua-potabledrenaje-y-saneamiento-2014.pdf

Conagua. (2015). Situación del Subsector de Agua Potable, Alcantarillado y Saneamiento. México: Semarnat, Comisión Nacional del Agua. Recuperado de https:// www.gob.mx/cms/uploads/attachment/file/108998/DSAPAS_2015.pdf

Conapo. (2010). Índice de marginación por entidad federativa y municipio, 2010. México: Consejo Nacional de Población. Recuperado de http://www.conapo. 
gob.mx/en/CONAPO/Indices_de_Marginacion_2010_por_entidad_federativa y_municipio

Córdova, R., Núñez, C. y Skerritt, D. (2007). Introducción: Nuevos escenarios de la migración en México. Veracruz como parte de los flujos migratorios a Estados Unidos. En R. C. Núñez y D. Skerritt (comps.), In God we trust. Del campo mexicano al sueño americano (pp. 9-33). México, Conacyt / Universidad Veracruzana.

Díaz Santos, M. G. (2014). Relaciones de poder en la gestión comunitaria del agua: el territorio y lo social como fuerzas (tesis de maestría). Flacso, México.

Domínguez Serrano, J. (2010). El acceso al agua y saneamiento: un problema de capacidad institucional local. Análisis en el estado de Veracruz. Gestión y Política Pública, 29(2), 311-350. Recuperado de http://www.scielo.org.mx/pdf/gpp/ v19n2/v19n2a4.pdf

Dupuits, E. (2014). Asociatividad y gestión comunitaria del agua en América Latina. Una construcción desde la CLOCSAS. Trabajo presentado en el Foro de los Recursos Hidricos. Recuperado de http://www.camaren.org/files/2014/08/ asociatividad.pdf

Escobar, C. (2015). Las asambleas comunitarias en Tlaxcala como eje de la gestión del agua: una experiencia de gobernanza colaborativa (tesis de doctorado). Flacso, México.

Fenapru. (2017). Aprobación del proyecto de Ley de Servicio Sanitario Rural. Por primera vez en Chile se trabaja en una ley con participación ciudadana [nota publicada el 16 de enero en el sitio oficial de Fenapru]. Santiago, Chile: Federación Nacional de Agua Potable Rural. Recuperado de http://fenapruchile. cl/2017/01/16/aprobacion-del-proyecto-de-ley-de-servicio-sanitario-rural-porprimera-vez-en-chile-se-trabaja-en-una-ley-con-participacion-ciudadana.html

Fondo para el Logro de los ODM. (2013). Lineamientos para la conformación de servicios mancomunados de agua potable y saneamiento en el Ecuador. Quito, Ecuador: Ministerio de Desarrollo Humano y Vivienda, Fondo para el Logro de los ODM.

Galindo Escamilla, E. y Palerm, J. (2007). Pequeños sistemas de agua potable: entre la autogestión y el manejo municipal en el estado de Hidalgo. Agricultura, Sociedad y Desarrollo, 4(2), 127-145. Recuperado de http://www.colpos.mx/ asyd/volumen4/numero2/asd-08-008.pdf

Galindo Escamilla, E. y Palerm, J. (2009). Las otras instituciones y el manejo eficiente del agua potable a pequeña escala: el Valle Tlazintla-Pozuelos, un caso de autogestión. Trabajo presentado en el XXXIV Simposio de Historia y Antropología, edición internacional "Tierra y agua: protagonistas de la historia", Hermosillo, Sonora, 23 a 27 de febrero.

González Méndez, M. G. (2013). El proceso de descentralización en la gestión del agua, a través de la eficiencia económica de los organismos operadores: estudio de caso en la zona centro del estado de Veracruz (tesis de maestría). Universidad Veracruzana.

Estudios Demográficos y Urbanos, vol. 33, núm. 2 (98), 2018, pp. 469-503

ISSN 0186-7210; e ISSN 2448-6515; doi: http://dx.doi.org/10.24201/edu.v33i2.1764 
González, A., Chávez, L. y Silva, E. (2011). III Foro de Manejo Comunitario del Agua, del 8 al 10 de junio de 2011 (memoria). Grupo de Estudios Ambientales / Fundación Gonzalo Río Arronte, Chilpancingo, Guerrero. Recuperado de http:// www.geaac.org/images/stories/DM_memoriaIIIforoAgua_010212.pdf

Guaillas Medina, S. (2013). La gestión comunitaria del agua mediante la alianza público-comunitaria. Trabajo presentado en el Foro de los Recursos Hidricos. Recuperado de http://www.camaren.org/files/2013/04/articulo3.pdf

Guerrero-de León, A., Gerritsen, P. R. W., Martínez-Rivera, L. M., Salcido-Ruiz, S., Meza-Rodríguez, D. y Bustos-Santana, H. (2010). Gobernanza y participación social en la gestión del agua en la microcuenca El Cangrejo, en el municipio de Autlán de Navarro, Jalisco, México. Economía, Sociedad y Territorio, 10(33), 541-567. Recuperado de http://www.scielo.org.mx/scielo.php?script=sci arttext\&pid=S1405-84212010000200009\&lng=es\&tlng=es

Gutiérrez Villalpando, V., Nazar-Beutelspacher, A., Zapata-Martelo, E., ContrerasUtrera, J. y Salvatierra-Izaba, B. (2013). Mujeres y organización social en la gestión del agua para consumo humano y uso doméstico en Berriozábal, Chiapas. LiminaR. Estudios Sociales y Humanísticos, 11(2), 100-113. Recuperado de http://www.scielo.org.mx/pdf/liminar/v11n2/v11n2a7.pdf

Hernández, J. A. (2016). Prossapys fases I, II, III y IV. Trabajo presentado en la mesa de trabajo Financiamiento de los sistemas de agua potable y saneamiento rural. Banco Interamericano de Desarrollo. Ciudad de México, 8 de abril.

INEGI. (1990). XI Censo General y de Población y Vivienda. México: Instituto Nacional de Estadística y Geografía. Recuperado de http:/www.beta.inegi.org. $\mathrm{mx} /$ proyectos/ccpv/1990/default.html

INEGI. (2010). Censo de Población y Vivienda 2010. México: Instituto Nacional de Estadística y Geografía. Recuperado de http://www.beta.inegi.org.mx/proyectos/ ccpv/2010/default.html

INEGI. (2011). Censo Nacional de Gobiernos Municipales y Delegaciones. México: Instituto Nacional de Estadística y Geografía. Recuperado de http://www.beta. inegi.org.mx/proyectos/censosgobierno/municipal/cngmd/2011/

INEGI. (2013). Censo Nacional de Gobiernos Municipales y Delegaciones. México: Instituto Nacional de Estadística y Geografía. Recuperado de http://www.beta. inegi.org.mx/proyectos/censosgobierno/municipal/cngmd/2013/

Jackman, R. W. y Miller, R. A. (1998). Social capital and politics. Annual Reviews of Political Science, 40(3), 47-73. Recuperado de https://crcresearch.org/filescrcresearch/File/jackman 98.pdf

Jiménez, R. (2011). La gestión social del agua: el Programa K030 en el distrito de riego 061, Zamora, Michoacán, México. Agricultura, Sociedad y Desarrollo, 8(3), 329-344. Recuperado de http://www.colpos.mx/asyd/volumen8/numero3/ asd-11-002.pdf

Krueger, R. A. (1991). El grupo de discusión: guía práctica para la investigación aplicada. Madrid, España: Pirámide.

Castro, J., y Lacabana, M. (2005). Agua y desarrollo en América Latina: por una

Estudios Demográficos y Urbanos, vol. 33, núm. 2 (98), 2018, pp. 469-503

ISSN 0186-7210; e ISSN 2448-6515; doi: http://dx.doi.org/10.24201/edu.v33i2.1764 
democracia sustantiva en la gestión del agua y sus servicios. Cuadernos del CENDES, 22(59), 9-15 Recuperado de http://www.scielo.org.ve/scielo. php?script=sci_arttext\&pid=S1012-25082005000200001

Ley 21 de Aguas del Estado de Veracruz-Llave. (2001). Ley número 21 de Aguas del Estado de Veracruz-Llave, Gaceta Oficial. Órgano del Estado de VeracruzLlave, 29 de junio. Recuperado de http://www.ordenjuridico.gob.mx/Documentos/ Estatal/Veracruz/wo77106.pdf

Ley 21 de Aguas del Estado de Veracruz-Llave. Reglamento. (2002). Reglamento de la Ley número 21 de Aguas del Estado de Veracruz-Llave. Gaceta Oficial del Estado de Veracruz, 28 de octubre. Recuperado de http://legismex.mty.itesm. $\mathrm{mx} /$ estados/ley-ver/VER-R-LeyAguas2010_06.pdf

Ley 72 de Agua y Saneamiento para el Estado de Veracruz-Llave. (1990). Decreto por el cual se expide la Ley Número 72 de Agua y Saneamiento para el Estado de Veracruz-Llave, Gaceta Oficial, 5 de junio.

Lockwood, H. (2002). Mecanismos de apoyo institucional para los sistemas rurales de agua potable y saneamiento manejados por las comunidades en América Latina. Environmental Health Project (EHP). Washington, DC. Recuperado de http://www.ehproject.org/PDF/Strategic_papers/EHP\%20SR-6SPANISH.pdf

López, S., Martínez, T. y Palerm, J. (2013). Las comunidades en la administración de sistemas de agua potable: región de los Volcanes, Estado de México. Agricultura, Sociedad y Desarrollo, 10(1), 39-58. Recuperado de http://www.colpos. $\mathrm{mx} / \mathrm{asyd} /$ volumen10/numero1/asd-12-013.pdf

Marín, R. (2016). Experiencias de dotación de agua en el ámbito rural en América Latina. Trabajo presentado en el Seminario El derecho humano al agua en el ámbito rural en Latinoamérica, El Colegio de México, A.C., Ciudad de México, 21 y 22 de enero.

Merino, L. (2008). Conservación comunitaria en la Cuenca Alta del Papaloapan, Sierra Norte de Oaxaca. Nueva Antropología, 21(68), 37-49. Recuperado de http:/ /www.scielo.org.mx/scielo.php?script=sci_arttext\&pid=S0185-06362 008000100003\&lng=es\&tlng=es

Merino Pérez, L. (2004). Conservación o deterioro. El impacto de las políticas públicas en las instituciones comunitarias y en los bosques de México. México: Secretaría de Medio Ambiente y Recursos Naturales / Instituto Nacional de Ecología / Consejo Civil para la Silvicultura Sostenible A.C.

Mestries, F. (2006). Entre la migración internacional y la diversificación de cultivos. Los pequeños productores de café en dos localidades de Veracruz. Sociológica, 21(60), 75-107. Recuperado de http://www.redalyc.org/pdf/3050/305024678004.pdf

Nicolas-Artero, C. (2016). Las organizaciones comunitarias de agua potable rural en América Latina: un ejemplo de economía substantiva. Polis, 15(45), 165-189. Recuperado de https://dx.doi.org/10.4067/S0718-65682016000300009

Organización Mundial de la Salud (OMS). (2013). Cólera en México. Actualización. Ginebra, Suiza: Organización Mundial de la Salud. Recuperado de http://www. who.int/csr/don/2013_11_13/es/ 
Ostrom, E. (2000). El gobierno de los bienes comunes. La evolución de las instituciones de acción colectiva. México: FCE.

Ostrom, E. y Ahn, T. K. (2003). Una perspectiva del capital social desde las ciencias sociales: capital social y acción colectiva. Revista Mexicana de Sociología, 1(3), 155-233. Recuperado de http://www.scielo.org.mx/pdf/rms/v65n1/v65n1a5.pdf

Palerm, J. (2002). Antología sobre pequeño riego. Sistemas de riego no convencionales (vol. 3). Colegio de Postgraduados. Recuperado de https://www.researchate. net/publication/262415060_Antologia_sobre_pequeno_riego_vol_III_Sistemas_ de_riego_no_convencionales

Palerm, J. (2003). Memorias del simposio El acceso al agua: un problema histórico y actual, en el marco del Congreso de Americanistas, Colegio de Postgraduados, Santiago de Chile, 14 al 18 de julio.

Palerm, J. y García Blanco, R. (2003). Memorias del simposio El acceso al agua: un problema histórico y actual, en el marco del Congreso de Americanistas, Colegio de Postgraduados, Santiago de Chile, 14 al 18 de julio.

Palma, R., Quesnel, A. y Delaunay, D. (2000). Una nueva dinámica de poblamiento rural en México: el caso del sur de Veracruz, 1970-1995. Apuntes sustantivos y metodológicos. En E. Léonard y E. Velázquez (eds.), El Sotavento veracruzano. Procesos sociales y dinámicas territoriales. México: IRD / CIESAS.

Paré, L. (2005). Monitoreo comunitario de la calidad y cantidad del agua en la microcuenca del Pixquiac. Cartel del Instituto de Investigaciones Sociales, Universidad Nacional Autónoma de México / Sendas A.C. / Global Water Watch.

Prats, J. O. (2003). El concepto y el análisis de la gobernabilidad. Instituciones y desarrollo. Instituciones y Desarrollo, 14-15, 239-269. Recuperado de https:// www.ses.unam.mx/docencia/2007II/Lecturas/Mod3_Oriol.pdf

Programa Agua para Siempre, Alternativas y Procesos de Participación Social A.C. (2017). Página oficial de Alternativas y Procesos de Participación Social A.C. México. Recuperado de http://www.alternativas.org.mx/index.html

Programa de las Naciones Unidas para el Desarrollo. (2011). Informe sobre desarrollo humano, sostenibilidad y equidad: un mejor futuro para todos. Washington, DC: Communications Development Incorporated.

Red Agua Segura. (2016). VII Encuentro de las OCSAS Latinoamericanas (nota periodística). Portal Red Agua Segura. Disponible en http://www.gestoresde aguasegura.org/portada/2016/11/02/vii-encuentro-de-las-ocsas-latinoamericanas/

Sandoval Moreno, A. (2011). Entre el manejo comunitario y gubernamental del agua en la ciénaga de Chapala, Michoacán, México. Agricultura, Sociedad y Desarrollo, 8(3), 367-385. Recuperado de http://www.colpos.mx/asyd/volumen8/ numero3/asd-11-005.pdf

Sandoval-Moreno, A. y Günther, M. G. (2013). La gestión comunitaria del agua en México y Ecuador: otros acercamientos a la sustentabilidad. Ra Ximhai, 9(2). Recuperado de http://www.redalyc.org/articulo.oa?id=46128964012

Soares, D. (2007). Acceso, abasto y control del agua en una comunidad indígena chamula en Chiapas: un análisis a través de la perspectiva de género, ambiente 
y desarrollo. Región y Sociedad, 19(38), 25-50. Recuperado de http://www. scielo.org.mx/pdf/regsoc/v19n38/v19n38a2.pdf

Torregrosa, A. y Kloster, K. (2006). Gestión, solidaridad y conflicto en torno al agua. El caso de Milpa Alta. En V. Vázquez, y D. Soares (coords.), Gestión y cultura del agua (tomo 2). México: Instituto Mexicano de Tecnología del Agua / Colegio de Posgraduados en Ciencias Agrícolas.

Villarroel, Novoa, C. (2012). Asociaciones comunitarias de agua potable rural en Chile: diagnóstico y desafíos. Santiago, Chile: Programa Chile Sustentable.

Zambrana, T. (2017), CLOCSAS: antecedentes, evolución y potencialidades, Madrid, España: Agencia Española de Cooperación Internacional para el Desarrollo.

Zurbriggen, C. (2014). Políticas latinoamericanas en la gestión del agua: de la gobernanza neoliberal a una gobernanza pública. Agua y Territorio, 3, 89-99. Recuperado de https://revistaselectronicas.ujaen.es/index.php/atma/article/ view/1427/1218

\section{Acerca de las autoras}

Judith Domínguez Serrano es doctora en Derecho por la Universidad Autónoma de Madrid. Es profesora investigadora del Centro de Estudios Demográficos, Urbanos y Ambientales de El Colegio de México, A.C., donde también funge como coordinadora del doctorado en Estudios Urbanos y Ambientales. Es miembro del Sistema Nacional de Investigadores (SNI), nivel II. Sus líneas de investigación son: política y derecho de aguas, derecho humano al agua y saneamiento, y gobernanza ambiental. Ha publicado los libros Derecho humano al agua y saneamiento (en coautoría con Joaquín Flores), 2016; El monitoreo social del agua y saneamiento para garantizar el derecho humano al agua (en coautoría con Diana Martínez, Anabel Palacios y Alejandra Peña), 2013; Hacia un posicionamiento de gobernanza del agua en México, 2012; La calidad del agua en México y España. Tratamiento jurídico y financiero (codirigido con Antonio Embid), 2011; y La prevención y control integrados de la contaminación, 2003.

Erandi Amor Castillo Pérez es estudiante del doctorado en el Programa de Estudios Urbanos y Ambientales en El Colegio de México, A.C. (2017-2021), es maestra en Desarrollo Regional por El Colegio de la Frontera Norte, y licenciada en Sociología por la Universidad Veracruzana. Su trabajo de investigación se centra en la gobernanza del agua en zonas metropolitanas y periferias urbanas. Su experiencia profesional en el ámbito de la consultoría 
versa sobre la regulación de los servicios de agua potable y saneamiento; diagnósticos y evaluación de los programas federalizados en agua potable y saneamiento; y métodos de evaluación y seguimiento de la política pública del agua.

Fecha de recepción: 5 de junio de 2017.

Fecha de aceptación: 24 de noviembre de 2017. 
